Geosci. Model Dev. Discuss., doi:10.5194/gmd-2016-241, 2016

Manuscript under review for journal Geosci. Model Dev.

Published: 16 November 2016

(c) Author(s) 2016. CC-BY 3.0 License.

\title{
An intercomparison of Large-Eddy Simulations of the Martian daytime convective boundary layer
}

\author{
Tanguy Bertrand ${ }^{1}$, Aymeric Spiga ${ }^{1}$, Scot Rafkin $^{2}$, Arnaud Colaitis ${ }^{1}$, François Forget ${ }^{1}$, and \\ Ehouarn Millour ${ }^{1}$ \\ ${ }^{1}$ Laboratoire de Météorologie Dynamique (UPMC/CNRS), Paris, France \\ ${ }^{2}$ SouthWest Research Institute, Boulder, CO, USA \\ Correspondence to: Tanguy Bertrand (tanguy.bertrand -a- lmd.jussieu.fr)
}

\begin{abstract}
Large-Eddy Simulations (LES) for Mars resolve the Planetary Boundary Layer (PBL) turbulent dynamics by using a very fine horizontal resolution of a few tens of meters. LES modeling is becoming a more and more useful tool to prepare the robotic exploration of Mars by providing means to evaluate the intensity of convective plumes and vortices, horizontal wind gustiness, and turbulent fluctuations of temperature in the Martian PBL. In such context, and given the relative paucity of turbulence-related measurements on Mars, an intercomparison of LES models is a fruitful way to evaluate the models' predictions and to indicate possible areas of improvement. Thus, to prepare the landing of the ExoMars Schiaparelli lander (also named ExoMars Demonstrator Module, EDM), scheduled for October 2016, the results of the Laboratoire de Météorologie Dynamique (LMD) and South-West Research Institute (SwRI) LES models have been compared. The objective of this study is to determine the range of uncertainties, and dispersions, of the two numerical models' predictions, for the critical phase of the spacecraft's descent in the Martian daytime turbulent PBL. First, a strategy is defined to ensure similar radiative forcing in both the LMD and SwRI models. Then, LES are performed over a flat terrain with and without large-scale ambient horizontal wind. The LMD and SwRI Martian LES models predict similar temporal evolution of the PBL and organization in the horizontal and vertical wind fields. However, the convective motions in the daytime PBL are more vigorous by a factor 1.5-2 in SwRI results than in LMD results, independently of the presence or not of ambient horizontal wind. This discrepancy is further investigated through sensitivity studies to surface conditions, ambient wind, and airborne dust loading.
\end{abstract}

\section{Introduction}

In the Martian atmosphere, the Planetary Boundary Layer (PBL) depth can reach about ten kilometres above the surface in the daytime, when it is prone to intense turbulent convection associated with strong radiative warming of the surface (e.g., Gierasch and Goody, 1968; Sutton et al., 1978; Schofield et al., 1997; Smith et al., 2006). Conversely, in the night, convective motions are inhibited by surface radiative cooling, which creates a near-surface stable layer, subsequently removed within about an hour after sunrise. As a result, the depth of the daytime PBL on Mars undergoes strong variations with both incoming sunlight (as determined by local time, season, and dust opacity) and surface thermophysical properties (thermal inertia and albedo). 
Geosci. Model Dev. Discuss., doi:10.5194/gmd-2016-241, 2016

Manuscript under review for journal Geosci. Model Dev.

Published: 16 November 2016

(c) Author(s) 2016. CC-BY 3.0 License.

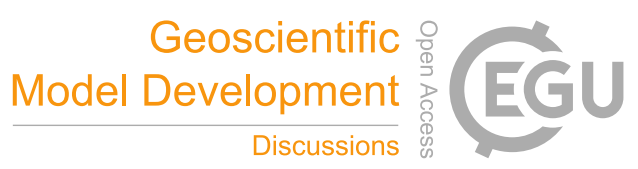

Furthermore, the regional variability of the PBL depth on Mars is controlled by altimetry (Hinson et al., 2008; Spiga et al., 2010), as well as ambient (i.e. regional and large-scale) wind (Tyler et al., 2008).

The turbulent PBL is a very dynamic part of the Martian atmosphere, characterized by abrupt changes in temperature, pressure, wind, and aerosols. These PBL variations have been characterized mostly by instrumented landers and rovers such 5 as the Viking spacecraft in the late 1970s (Sutton et al., 1978), Pathfinder in the late 1990s (Schofield et al., 1997), Mars Exploration Rovers and Mars Phoenix in the 2000s (Smith et al., 2006; Whiteway et al., 2009) - while Martian orbiters provided measurements of PBL depth (Hinson et al., 2008), as well as imagery of PBL-induced phenomena such as dust devils (Thomas and Gierasch, 1985) and cloud streets (Malin and Edgett, 2001). Despite this set of observations, the coverage of the Martian PBL activity has remained sparse thus far compared to e.g. what has been made available for the Earth's PBL.

A complementary approach to observations to study Mars' PBL is the use of numerical modeling. Three-dimensional turbulence-resolving Large-Eddy Simulations (LES) have been employed since the early 2000s to assess the intense daytime PBL dynamics on Mars (Rafkin et al., 2001; Toigo and Richardson, 2003; Spiga and Forget, 2009; Gheynani and Taylor, 2011), which includes convective vortices generating the observed dust devils (Spiga et al., 2016, for a review). In LES, using a horizontal resolution of some tens of meters permits to resolve the larger turbulent eddies, which are the source of most of the energy transport within the PBL (Lilly, 1962). Given the relative paucity of PBL measurements on Mars, LES models are of crucial importance to help understanding the PBL processes, thus broadening our knowledge of the atmospheric circulations on Mars at all scales (from planetary scales to turbulent scales). LES have also become powerful tools to prepare Martian exploration, since they are being used to characterize atmospheric hazards in the Entry, Descent and Landing (EDL) phase of a spacecraft, and in turn to help define the design of the landing system (Kass et al., 2003; Rafkin and Michaels, 2003; Tyler et al., 2008).

At the time of writing, several LES models for Mars are available in the community to characterize Martian PBL dynamics (cf. reference above, plus Michaels and Rafkin, 2004; Richardson et al., 2007; Tyler et al., 2008; Spiga et al., 2010). All published LES describe the same qualitative behaviour: a deeply convective PBL during daytime, starting with a gradual growth of the mixed layer in the morning and ending with a rapid stabilization in the end of the afternoon, associated with polygonal horizontal cells, thermal plumes and convective vortices. However, not only the various models do not share the same characteristics, but quantitative estimates were found to differ when predictions from various Martian LES models were compared for EDL studies (Kass et al., 2003). A systematic intercomparison between at least two existing Martian LES models is still yet to be carried out to further characterize those differences. This is what is proposed in the present study.

The need to evaluate the differences predicted by two distinct Martian LES is threefold:

1. Contrary to observational data, an estimate of the uncertainties of LES predictions is still lacking. This is especially critical for the studies of atmospheric hazards during EDL, given the central role that LES predictions play in those studies and the relative paucity of available data to characterize the Martian PBL dynamics (e.g. for vertical winds). Comparing LES models would thus enable to identify the uncertainties in their diagnostics, thereby enabling an optimal EDL design for both landing spacecraft and definition of landing ellipse. 
Geosci. Model Dev. Discuss., doi:10.5194/gmd-2016-241, 2016

Manuscript under review for journal Geosci. Model Dev.

Published: 16 November 2016

(c) Author(s) 2016. CC-BY 3.0 License.

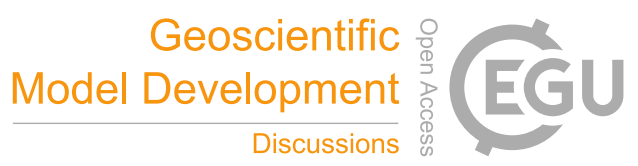

2. Carrying out a LES intercomparison would highlight discrepancies between results and help to identify the specific areas in which model improvements would be the most helpful. This overarching goal is beneficial for the whole Martian science. For instance, turbulent wind variability (i.e. "gustiness") plays an important role in controlling dust lifting on Mars (e.g., Mulholland et al., 2015, and references therein). Since turbulent wind measurements on Mars are very incomplete, LES predictions are still being an important source to assess the wind conditions on Mars associated with dust lifting (Fenton and Michaels, 2010). More generally, the continued development of Martian LES models is also of crucial importance to better understand the mechanisms responsible for heat and momentum transfer both by daytime PBL mixing and surface-atmosphere interactions. Following the tendency drawn by terrestrial studies, Martian LES predictions are more and more used to build and improve PBL parameterizations in Global Climate Models (GCMs) for Mars (Colaïtis et al., 2013).

3. Since Martian LES rely on hydrodynamical solvers inherited from terrestrial studies, confronting those models to the intense PBL convection on Mars (compared to the Earth, cf. Spiga, 2011) provides a stringent test for those solvers. An intercomparison study of Martian LES will ultimately be a strong driver of improvement for the atmospheric models used to carry out LES on Earth, and in an increasingly diverse range of planetary conditions (e.g. Venus LES, Barth and Rafkin, 2007; Imamura et al., 2014; Lefèvre et al., 2016).

In this paper, we compare the LES results obtained by, on the one hand, the Laboratoire de Météorologie Dynamique (LMD) Martian mesoscale model (Spiga and Forget, 2009; Spiga et al., 2010) and, on the other hand, the SouthWest Research Institute (SwRI) Martian mesoscale model (Rafkin et al., 2001; Michaels and Rafkin, 2004). We develop a strategy which makes our intercomparison study the first one of its kind for Mars: we ensure that similar physical constants and radiative forcing are employed in both models before performing a comparative analysis of LES results and conclude on the performance of the two dynamical solvers in predicting Mars' PBL convective motions. We further complement this intercomparison study by an exploration of the sensitivity of the convective PBL predicted by the LMD LES to surface thermophysical properties (e.g. albedo), ambient wind, and atmospheric dust loading.

We perform the present LES intercomparison in the context of the European Space Agency (ESA) ExoMars 2016 mission (hereinafter referred as ExoMars) with the aim of providing constraints for the EDL of the ExoMars Demonstrator Module (EDM, also named Schiaparelli). LES modeling is therefore performed at the ExoMars landing site, namely in the Terra Meridiani region (latitude $-1.82^{\circ} \mathrm{N}$, longitude $-6.15^{\circ} \mathrm{E}$ ), for the landing scheduled in northern autumn (solar longitude $L_{s}=$ $\left.244^{\circ}\right)$.

In Section 2, we describe the LMD and SwRI models used in this LES intercomparison. In section 3, we provide details on the intercomparison strategy, and how we reached similar radiative forcing both in SwRI and LMD LES. The results of both the Martian LES intercomparison and sensitivity study are discussed in section 4. We conclude about the similarities vs. discrepancies between the two models in section 6 . 
Geosci. Model Dev. Discuss., doi:10.5194/gmd-2016-241, 2016

Manuscript under review for journal Geosci. Model Dev.

Published: 16 November 2016

(c) Author(s) 2016. CC-BY 3.0 License.

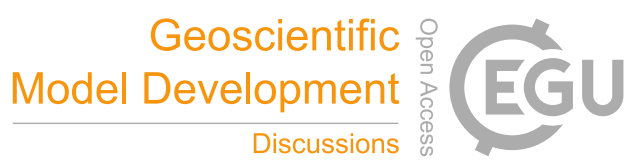

(c) (i)

\section{Models description}

We provide here the key points to describe the two models used for our LES intercomparison. Further details about each model can be found in the references provided in this section.

Both LMD and SwRI Martian LES models have been built independently by adapting terrestrial mesoscale models to the

5 Martian case, with the coupling of specific physical models (namely, radiative transfer and soil model) initially developed for Martian GCMs:

- LMD LES are performed using the LMD Martian Mesoscale Model (Spiga and Forget, 2009; Spiga et al., 2010), based on the Weather Research and Forecast (WRF) model and its fully compressible non-hydrostatic dynamical core (Moeng et al., 2007; Skamarock and Klemp, 2008), combined with the comprehensive set of physical parametrizations of the LMD GCM (Forget et al., 1999).

- SwRI LES are performed using the Mars Regional Atmospheric Modeling System (MRAMS), a nonhydrostatic Martian mesoscale model developed at SwRI (Rafkin et al., 2001; Michaels and Rafkin, 2004) and based on the terrestrial RAMS dynamical core (Pielke et al., 1992), which physical parameterizations are inherited from the Martian NASA Ames GCM (Haberle et al., 1993).

The two LES models not only use very distinct different radiative transfer and soil model (inherited from GCM), but also use different dust scattering properties (Ockert-Bell et al. (1997) for SwRI LES vs. Wolff et al. (2009) for LMD LES), which can lead to significant departures in the predictions of atmospheric temperatures.

Although the largest turbulent eddies (contrary to global and regional climate models) are resolved, LES still lack the mixing produced by the unresolved small-scale eddies, which requires the inclusion of parameterizations for subgrid-scale diffusion. In the two models used for this intercomparison, the resolved large-eddy Turbulent Kinetic Energy (TKE) can be used to assess the strength of small-scale mixing in the parameterization, which is usually effective on the three spatial coordinates rather than the sole vertical dimension. The SwRI Martian LES model contains a specific Deardorff diffusion scheme (Deardorff, 1980), also used in the terrestrial version of MRAMS. The LMD LES model uses the strategy adopted for WRF terrestrial LES (Moeng et al., 2007), which is similar qualitatively to the one adopted by SwRI with MRAMS - although subgrid-scale mixing coefficients differ between LMD and SwRI LES (see Section 4 and 6). Both models use a (qualitatively similar) Richardsonbased surface layer to compute surface-atmosphere transfers of heat, momentum, and tracers (transfer coefficients vary with atmospheric stability, see e.g. Colaitis et al., 2013).

Although the dynamical and physical parts of the LMD and SwRI LES models are different, the simulation framework in both models is similar. To resolve the 3-D convective plumes, cells and vortices, LES are performed on a domain using periodic boundary conditions, with horizontal and vertical resolutions of a few tens of meters. The radiative transfer models in LES are combined with a horizontally uniform and static dust profile. Surface properties (topography, albedo, thermal inertia) are uniform too in the LES domain. The models typically compute 10 Martian hours during daytime to capture the convective 
Geosci. Model Dev. Discuss., doi:10.5194/gmd-2016-241, 2016

Manuscript under review for journal Geosci. Model Dev.

Published: 16 November 2016

(c) Author(s) 2016. CC-BY 3.0 License.

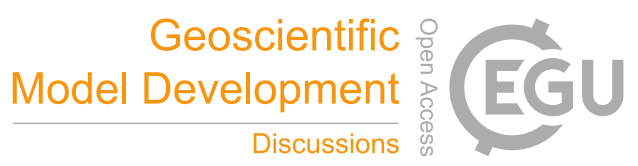

(c) (i)

PBL rise, growth and collapse. In both the LMD and SwRI models, a random (noise) perturbation of $0.1 \mathrm{~K}$ amplitude is added to the initial temperature field to break its symmetry and help trigger convective motions (Michaels and Rafkin, 2004).

\section{Intercomparison methodology}

Since the LMD and SwRI models use a combination of very distinct radiative transfer modeling, dust properties, and subsur-

5 face modeling, a preliminary preparation of models is necessary to prevent the LES intercomparison from being simply an intercomparison of radiative transfer schemes, in the radiatively-controlled (by dust and $\mathrm{CO}_{2}$ ) Martian environment. This is actually one of the reasons why a systematic intercomparison study between mesoscale models or LES for Mars has not been carried out yet: thus far the models used for comparisons did not use similar radiative forcing, making the analysis of dynamical differences rather cumbersome, although the dispersion of simulated results remained informative about differences between models (e.g. Kass et al., 2003). Conversely, what is aimed in the present intercomparison study is to assess the departures in PBL dynamics possibly arising from the use of two distinct LES models - rather than departures resulting from combined differences in the dynamical core and physical parameterizations. To that end, not only we use the closest possible LES settings between LMD and SwRI modeling framework (section 3.1), but we also ensure that the same radiative forcing of the atmospheric flow is imposed in the LMD and SwRI models (section 3.2), thereby enabling us to conduct consistent dynamical comparisons of both LES models in section 4.

\subsection{General settings}

The main settings used in LMD and SwRI LES are summarized in Tables 1 (model parameters) and 2 (planetary constants). The rationale for those choices is to reach a high level of similarity in both models as far as model domain, planetary constants and initial conditions are concerned.

The computational domain has to be wide enough to contain several convective cells (Mason, 1989), in order to derive consistent PBL statistics from LES results. At the same time, the horizontal resolution must be fine enough to enable a good representation of the "large eddy" part of the turbulence spectra. Hence the choice for an horizontal resolution of $50 \mathrm{~m}$ and $145 \times$ 145 grid points (this configuration provides similar PBL statistics as other configurations with more grid points, as is detailed in Spiga et al., 2010). A model top at $12 \mathrm{~km}$ above the local surface is used, high enough to ensure that the boundary layer growth will not be influenced by the position of this model top.

The LES models are run with 150 (SwRI) and 201 (LMD) vertical levels, which yields a vertical resolution of approximately $80 \mathrm{~m}$ and $60 \mathrm{~m}$ respectively in the vertical dimension. Given the type of vertical coordinates employed in each model (WRF uses mass-based coordinates, a slightly different version of sigma coordinates than what is used in RAMS), this difference of vertical resolution is imposed by the typical set of vertical levels which optimizes the performance of physical parameterizations for each model. However, based on the sensitivity study carried out in Spiga et al. (2010), this difference in vertical resolution does not affect significantly the PBL predictions through LES. The key requirement is that the vertical resolution is refined to a few meters close to the surface, which is ensured in both models. 
Geosci. Model Dev. Discuss., doi:10.5194/gmd-2016-241, 2016

Manuscript under review for journal Geosci. Model Dev.

Published: 16 November 2016

(c) Author(s) 2016. CC-BY 3.0 License.

\begin{tabular}{|l|l|}
\hline Parameter & Model settings for the intercomparison \\
\hline Horizontal grid (x,y) & $145 \times 145$ \\
Horizontal resolution & $50 \mathrm{~m}$ \\
Vertical grid & 201 levels (LMD) - 150 levels (SwRI) \\
Vertical resolution & $60 \mathrm{~m}(\mathrm{LMD})-80 \mathrm{~m}$ (SwRI) \\
Model top & $12 \mathrm{~km}$ \\
Dynamical time step & $0.5 \mathrm{~s}$ \\
Region & $-1.82^{\circ} \mathrm{N} ;-6.16^{\circ} \mathrm{E}$ (Meridiani Planum - ExoMars 2016 landing site) \\
Solar Longitude & $244^{\circ}$ (Landing date, northern autumn) \\
Surface conditions & Albedo: $0.21-$ Thermal inertia: 238 tiu (adjusted to 300 tiu in the LMD LES, see Section 3.2) \\
Dust vertical distribution & Conrath type: $P_{0}=610$ Pa and $\nu=0.007$ \\
Dust opacity & $\tau=0.2$ (horizontally uniform and constant over time) \\
Initial temperature profile & $\begin{array}{l}\text { Extracted from LMD-GCM run with uniform dust loading of } \tau=0.2 \text { at geographical coordinates } \\
\text { and } L_{s} \text { of the ExoMars reference landing site (Meridiani region) } \\
\text { Ambient wind }\end{array}$
\end{tabular}

Table 1. LMD and SwRI LES models settings and configurations for the intercomparison.

\begin{tabular}{|c|c|c|c|c|c|c|}
\hline$c_{p}\left(\mathrm{~J} . \mathrm{kg}^{-1} \cdot \mathrm{K}^{-1}\right)$ & $r\left(\mathrm{~J} \cdot \mathrm{kg}^{-1} \cdot \mathrm{K}^{-1}\right)$ & $g\left(\mathrm{~m} \cdot \mathrm{s}^{-2}\right)$ & $\epsilon$ & $s_{h c}\left(\mathrm{~J} \cdot \mathrm{kg}^{-1} \cdot \mathrm{K}^{-1}\right)$ & $s_{r h o}\left(\mathrm{~kg} \cdot \mathrm{m}^{-3}\right)$ & $D_{s}(\mathrm{~s})$ \\
770 & 192 & 3.72 & 0.99 & 711 & 1500 & 88775.244 \\
\hline$\Phi$ & $e$ & $s m a(\mathrm{AU})$ & $L_{y r}(\mathrm{sol})$ & $S_{0}\left(\mathrm{~W} \cdot \mathrm{m}^{-2}\right)$ & $\Omega\left(\mathrm{rad} . \mathrm{s}^{-1}\right)$ & $R_{M}(\mathrm{~m})$ \\
25.1919 & 0.09341233 & 1.52366231 & 669 & 1367 & $7.08821 \mathrm{e}-5$ & 3390000 \\
\hline
\end{tabular}

Table 2. Physical and planetary constants for the Martian atmosphere, as defined in the models: $c_{p}$ is the specific heat capacity, $r$ is the specific gas constant, $g$ is the gravitational acceleration, $\epsilon$ is the ground emissivity, $s_{h c}$ is the subsurface specific heat and $s_{r h o}$ is the subsurface density. $D_{s}$ is the duration of a sol, $\Phi$ is the planet obliquity, $e$ is the eccentricity of the planet orbit, sma is its semi major axis, $L_{y r}$ is the number of sols in one Martian year, $S_{0}$ is the solar constant at $1 \mathrm{AU}, \Omega$ is the planetary rotation rate and $R_{M}$ is Mars radius.

For the chosen grid spacing, the dynamical time step is set to be small enough to ensure numerical stability according to CFL criterion, but it has also to be high enough to reduce the usually expensive computational cost of LES - especially given that sensitivity runs are included in this intercomparison study. Thus, a good trade-off for the LES timestep has been found to be $0.5 \mathrm{~s}$. LES are carried out from local times 06:00 to 18:00. The comparison of the results is mainly performed between

5 11:00 to 17:00 local time since convective motions are usually amongst the strongest around these local times. Furthermore, this range was convenient to assess ExoMars landing atmospheric conditions since the spacecraft is designed to land in the local-time window of 14:00-16:00.

As is mentioned in the introduction, the LES were performed to assess atmospheric hazards for the ExoMars mission. Therefore both surface thermophysical properties and initial temperature profile reflect the conditions at the expected season (end of 
Geosci. Model Dev. Discuss., doi:10.5194/gmd-2016-241, 2016

Manuscript under review for journal Geosci. Model Dev.

Published: 16 November 2016

(c) Author(s) 2016. CC-BY 3.0 License.

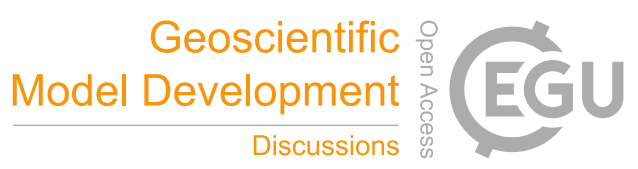

(c) (i)

northern autumn, areocentric longitude $L_{s}=244^{\circ}$ ) and location (Terra Meridiani, latitude $-1.82^{\circ} \mathrm{N}$, longitude $-6.15^{\circ} \mathrm{E}$ ) for the ExoMars landing. Thermal inertia is set to $238 \mathrm{~J} \mathrm{~s}^{-\frac{1}{2}} \mathrm{~m}^{-2} \mathrm{~K}^{-1}$ (unit hereinafter referred to as tiu for "thermal inertia unit") and albedo to 0.21 - those values are extracted from the Thermal Emission Spectrometer (TES) nighttime data, averaged over a $1000 \mathrm{~km}^{2}$ location around the ExoMars landing site. LMD and SwRI runs use the same initial temperature profile at $06: 00$

5 local time, extracted at the season and location of ExoMars' landing, from a run with the LMD GCM (Forget et al., 1999) performed with a constant and uniform dust opacity of 0.2 , as well as a Conrath-type dust vertical distribution (as is detailed in Pollack et al., 1990; Forget et al., 1999). Both LMD and SwRI LES also use these settings for dust opacity and dust vertical distribution. Setting a dust opacity of 0.2 might be an underestimate for the actual value at this season on Mars (Montabone et al., 2015), which ranges $0.3-0.5$, but assuming a clear atmosphere ensures the most unstable situation, thus the maximum strength for convection in LES runs (see Figure 17). Since this study's focus is on highlighting differences in convective PBL predictions, a more convective situation yields a more stringent test for LES models.

\subsection{Reaching a similar radiative forcing in the two compared models}

The two LES models we aim to compare share a fair amount of similar settings, as detailed in section 3.1. As is discussed in the beginning of this section 3, this similarity is necessary but not sufficient to ensure a consistent intercomparison of the LES predictions for the PBL dynamics on Mars. Despite our efforts, the fact that the LMD and SwRI models employ different radiative transfer schemes and dust properties leads to large temperature differences between the models, which overwhelms or at least competes with - dynamical differences. It would thus be challenging to ascribe the intercomparison differences to either radiative or dynamical differences.

A complete rewrite of either the LMD or SwRI LES to couple the same set of physical parameterizations is not possible in a reasonable amount of time. Hence the solution we found is to modify a small amount of key parameters in the LMD radiative scheme, so that it replicates SwRI radiative transfer predictions and ensures that the radiative forcing of the PBL in the LMD and SwRI LES are similar. Those key parameters are mostly related to dust optical properties (given the strong radiative control of dust on the Martian atmospheric structure, e.g. Gierasch and Goody (1972)) and surface thermophysical properties (albedo, thermal inertia), which controls the surface thermal balance in the Martian environment where atmospheric density is so low that the impact of sensible heat flux on this balance is not prominent (e.g. Savijärvi and Kauhanen, 2008).

We performed the comparisons and corrections using the single-column version (1D) of the respective physical parameterizations used in the LMD and SwRI LES models. All settings of those 1D models are similar to what is described in Tables 1 and 2 for the LES runs, and correspond to ExoMars landing location and season. For the sake of comparison, the same fine vertical resolution has been chosen for simulations with the LMD and SwRI models. The 1D models do not integrate any hydrodynamical equation: an ambient wind of $10 \mathrm{~m} \mathrm{~s}^{-1}$ is only imposed to obtain a realistic value for the sensible heat flux, whose influence on surface temperature is small but not negligible. Convective adjustment, that is usually included in 1D models to model mixing by turbulent plumes resolved by LES, is turned off in the 1D models as is the case in LES integrations. The radiative response of the LMD and SwRI 1D models is assessed by comparing the obtained equilibrium temperature profiles. 
Geosci. Model Dev. Discuss., doi:10.5194/gmd-2016-241, 2016

Manuscript under review for journal Geosci. Model Dev.

Published: 16 November 2016

(c) Author(s) 2016. CC-BY 3.0 License.
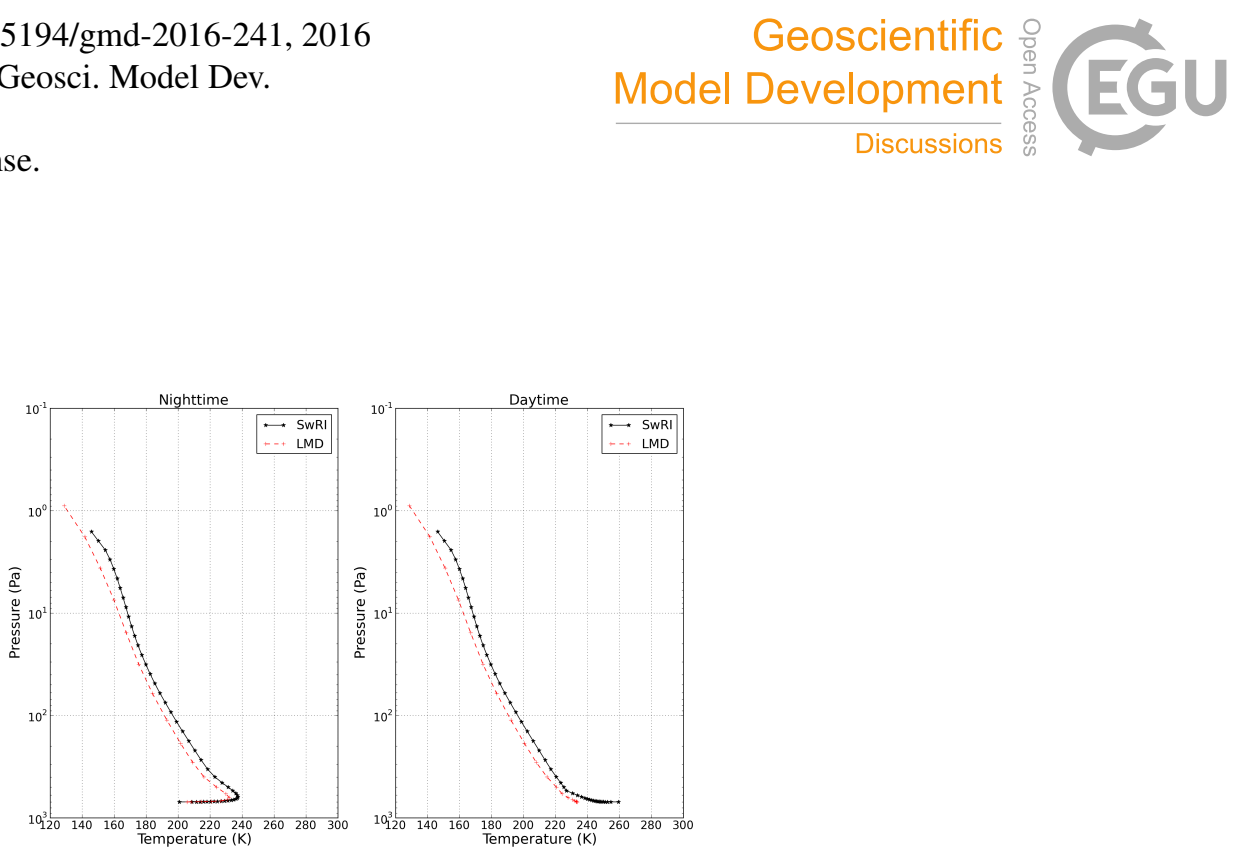

Figure 1. Temperature profiles obtained by LMD (red) before any adjustment and SwRI (black) 1D models at the ExoMars landing site and season. Left are temperatures at local time $00: 00$, right are temperatures at $12: 00$.

A match between the two profiles predicted by the 1D models means that the PBL dynamics in both the LMD and SwRI LES are forced by similar (unstable) gradients of vertical temperature imposed by radiative forcing.

The same initial temperature profile is used in the LMD and SwRI 1D models. This initial profile was obtained by running the LMD 1D model during 50 Martian days (repeating the same day corresponding to $L_{s}=244^{\circ}$ conditions). A simulation duration of 50 Martian days is large enough to reach steady-state equilibrium given the short radiative timescales of the Martian atmosphere (this was checked in practice in our 1D simulations). This profile is then used to initialize both the LMD and SwRI models, which are subsequently run for an additional 50 Martian days to ensure that the steady-state equilibrium is reached. In any case, although using the same initial temperature profile is helpful for consistency, results are not very sensitive to the assumed initial profile, owing to (again) the short radiative timescales of the Martian atmosphere.

In Figure 1 and Figure 2, we show the two temperature profiles and the surface temperatures obtained by the LMD and SwRI 1D models prior to any correction. To first order, the temperature profiles appear similar. Nonetheless, atmospheric temperatures in the LMD model are found to be $5-10 \mathrm{~K}$ colder than SwRI temperatures. This bias extends over almost the entire atmospheric column. In addition, LMD daytime surface temperatures are up to $8 \mathrm{~K}$ warmer than SwRI results. This further justifies the approach adopted in this section 3.2.

Our working assumption is that, given the central role played by dust on controlling the Martian thermal structure, modifying key dust radiative properties would enable us to obtain a match between the temperature profiles predicted by the LMD and SwRI models. We chose to vary 1. the dust extinction efficiency $Q_{e x t}$ (or "thermal infrared opacity", at the reference infrared wavelength) and 2. the visible single scattering albedo $w_{0}$, which quantifies dust "brightness" (further details and explanations in Forget et al., 1999; Madeleine et al., 2011). For the sake of simplicity, we define the ratios $S$ and $C$ of the corrected value over the reference value for respectively $w_{0}$ and $Q_{e x t}$ in the LMD model. The higher $S$, the brighter dust; the higher $C$, the stronger absorption by dust in the infrared. 
Geosci. Model Dev. Discuss., doi:10.5194/gmd-2016-241, 2016

Manuscript under review for journal Geosci. Model Dev.

Published: 16 November 2016

(c) Author(s) 2016. CC-BY 3.0 License.
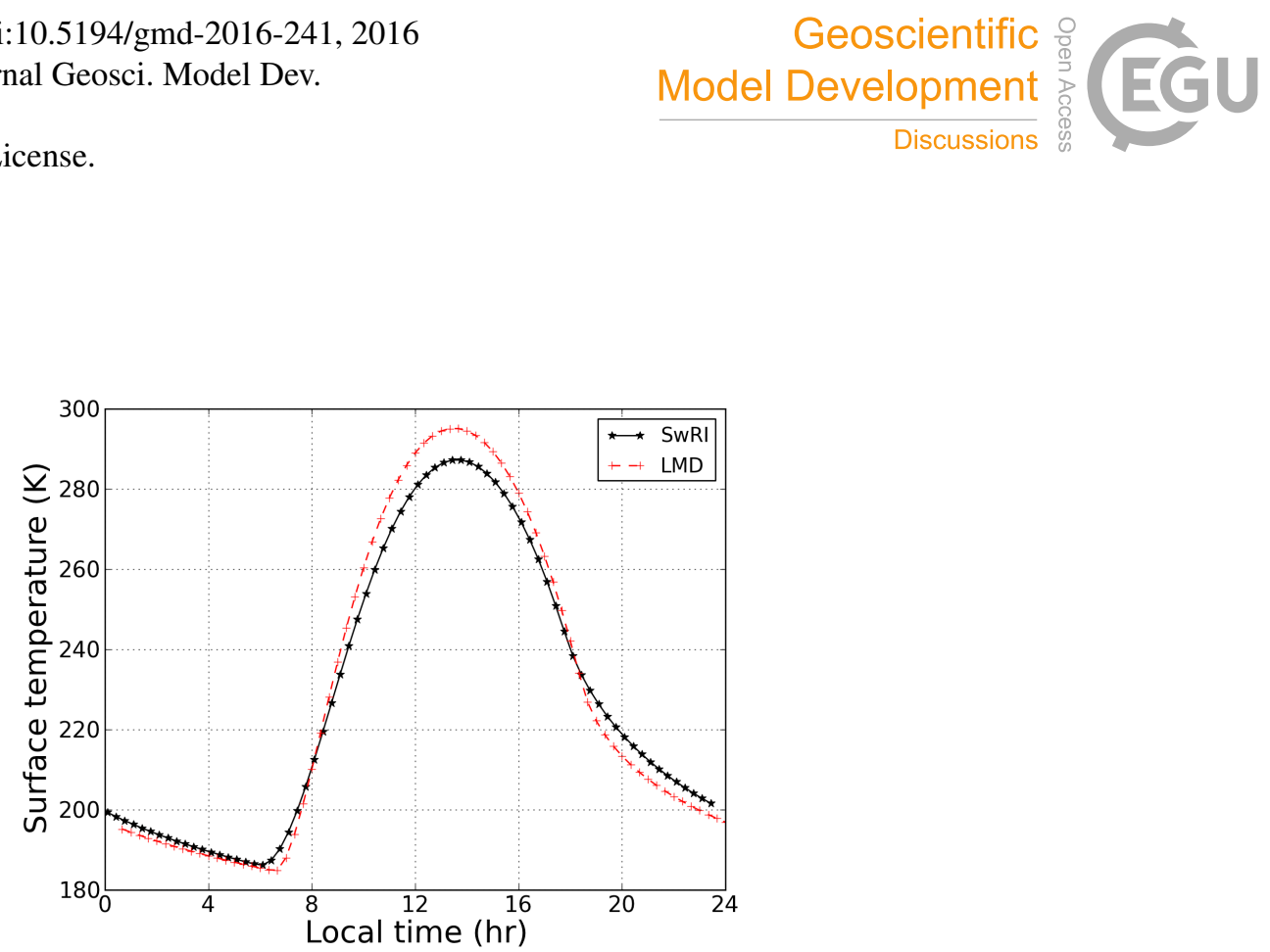

Figure 2. Preliminary comparison of LMD (red) and SwRI (black) surface temperatures at ExoMars landing site, before any adjustment, obtained with 1D models. The $8 \mathrm{~K}$ temperature gap around noon highlights the differences between both radiative models.

Figure 3 shows the sensitivity of the temperature profiles to $S$ and $C$. Here, the comparison of profiles is focused above PBL because in 1D PBL is parameterized while it is resolved in LES (see next section for comparisons within the PBL). We performed a comparative study for all local times, given that LES runs span stability conditions from highly unstable around noon to highly stable in early morning and late afternoon. For the sake of illustration, we show in the aforementioned figures typical nighttime and daytime temperature profiles at local times $0: 00$ and $12: 00$. In the clear atmosphere case we adopted (setting dust opacity to 0.2 ), dust brightness $S$ has a strong impact on the temperature profiles: a decrease of $20 \mathrm{~K}$ is obtained in nearly the whole atmospheric column when increasing $S$ from 0.92 to 1.04. Indeed bright dust means higher dust albedo, hence increased reflection of solar flux to space, and colder atmosphere and surface. The dust extinction ratio $C$ has a lesser impact (though not negligible) than $S$ on the thermal structure, as shown by Figure 3. This is expected for a clear atmosphere, where dust absorption in the infrared is not significant enough to cause a strong heating of the atmosphere (contrary to dust storm conditions). This sensitivity study shows that the values of the dust visible scattering albedo and extinction efficiency should be decreased to simulate the effect of dust aerosols both darker and more strongly absorbing in the infrared. The effect of this correction is to warm the atmosphere (both during daytime and nighttime).

As the tuning of these dust parameters does not change significantly the surface temperatures (because of the relatively clear atmosphere considered), the surface thermal inertia has also been changed in the LMD model so that it replicates the SwRI diurnal cycle, at least during daytime when the surface temperatures impact the PBL. Many optimization loops have been performed to replicate in an optimal way the MRAMS-Ames temperatures at all local times, taking into account the change of surface temperature as well. By increasing the thermal inertia up to 300 tiu (which remains close to the surface conditions encountered at ExoMars landing site), we decrease the LMD surface temperatures of about $8 \mathrm{~K}$ around noon and replicate the 
Geosci. Model Dev. Discuss., doi:10.5194/gmd-2016-241, 2016

Manuscript under review for journal Geosci. Model Dev.

Published: 16 November 2016

(c) Author(s) 2016. CC-BY 3.0 License.
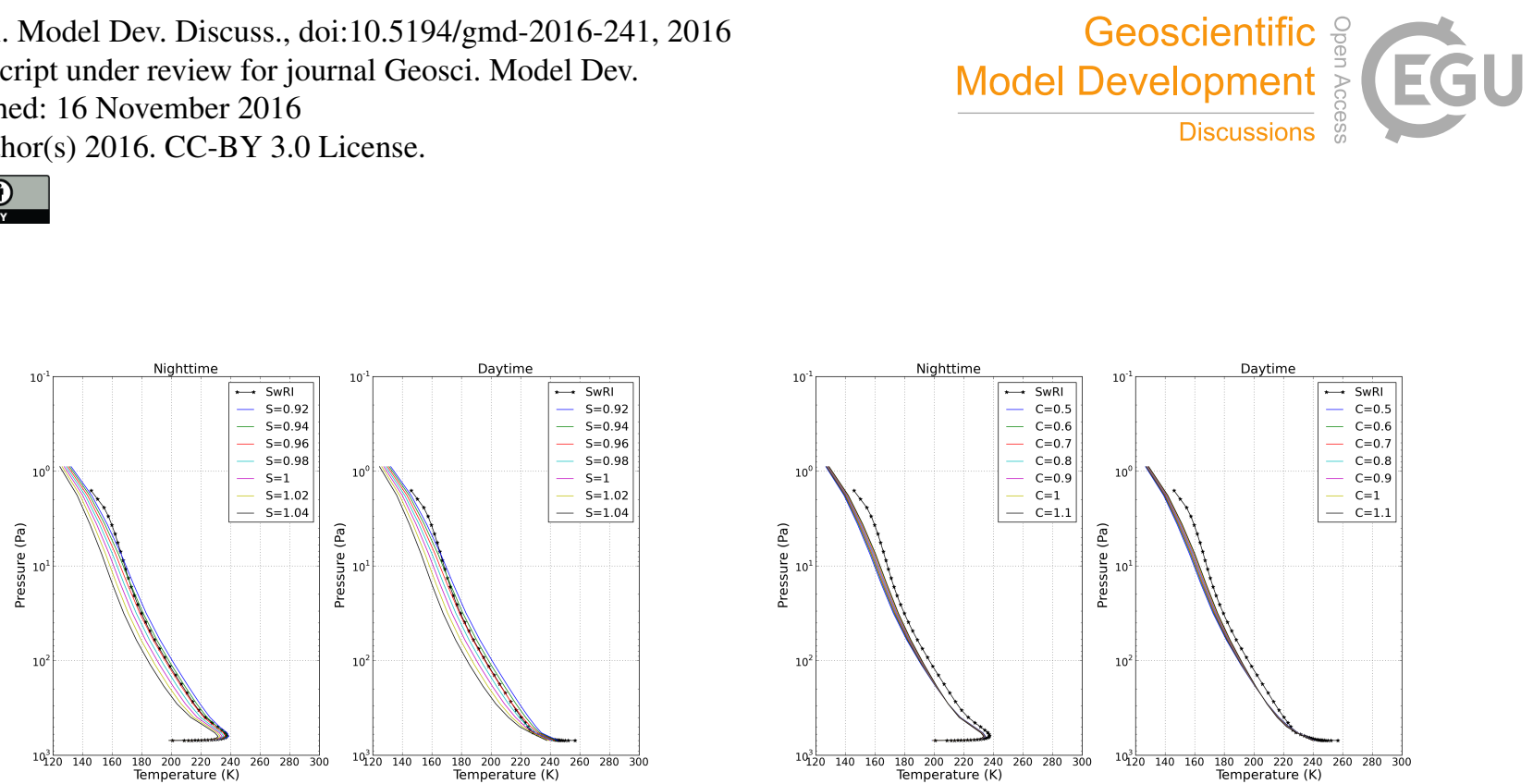

Figure 3. Top: sensitivity of LMD 1D temperature profiles to the dust brightness $S$. Left are temperatures at local time 00:00, right are at 12:00. SwRI 1D temperature profile is shown for reference in black. Bottom: Same figures, but for sensitivity to the dust thermal infrared opacity $C$.
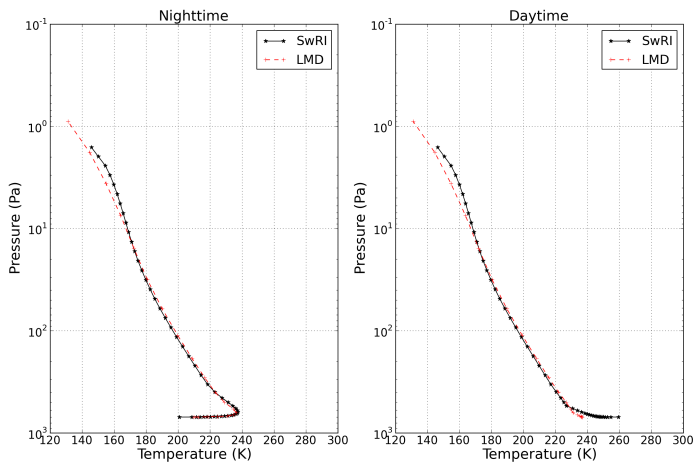

Figure 4. Same as Figure 1 with $S=94 \%$ and $C=70 \%$ in the LMD 1D model.

SwRI daytime surface temperatures, as shown in Section 4.1 by Figure 5. Values of $S=94 \%$ and $C=70 \%$ are used, in order to bridge the $5-10 \mathrm{~K}$ gap between the LMD and SwRI temperature profiles ( Figure 4).

\section{Comparison of LES results}

This section compares the LMD and SwRI LES results, obtained using the settings described by Table 1 and Table 2, with the

5 modified radiative transfer properties detailed in section 3.2 which allow a similar radiative forcing between the two models ( $S=94 \%, C=70 \%$ and thermal inertia $=300$ tiu). Two main test cases are considered: LES devoid of any ambient wind, and LES with an ambient wind of $15 \mathrm{~m} \cdot \mathrm{s}^{-1}$, thereby providing typical LES results of Martian daytime boundary convection in windless and windy conditions at the ExoMars landing site. 
Geosci. Model Dev. Discuss., doi:10.5194/gmd-2016-241, 2016

Manuscript under review for journal Geosci. Model Dev.

Published: 16 November 2016

(c) Author(s) 2016. CC-BY 3.0 License.

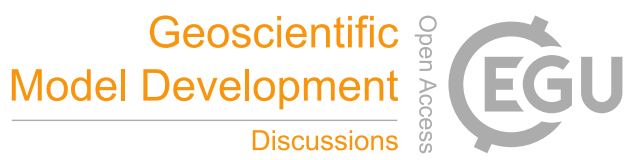

(c) (i)

\subsection{Forcing of PBL activity}

The PBL activity and its evolution are controlled by the surface temperature and the surface incident solar flux. As described in section 3, the preliminary steps of convergence of both models enabled a similar forcing to be reached, as shown by Figure 5. During daytime, discrepancies between LMD and SwRI LES surface temperatures are less than $1 \mathrm{~K}$. In addition, we also checked that the atmosphere above the PBL is controlled by similar radiative forcing in both models, as is found in the previous section with the 1D models. With these settings, any difference observed in the LES results (PBL depth, maximum updrafts...) will not be related to differences in "background" radiative thermal structure, but rather to different dynamical approaches in both models. Furthermore, the two models use different PBL near-surface stability schemes, which may also impact the results (see Figure 8 and Sections 4.2.1 and 6).

\subsection{Comparison of typical LES wind structures}

In this section we analyze the turbulent wind structures in order to verify if they are similar in both models and consistent with typical LES diagnostics. Note that the ambient wind is westward in the simulations.

\subsubsection{Wind structures and small scale variability}

Figure 9 shows horizontal sections of vertical winds at about $250 \mathrm{~m}$ and $2 \mathrm{~km}$ above the surface and at local time 11:00, obtained without ambient wind. Both models predict a horizontal organization of vertical winds into polygonal cells with narrow updrafts on the ridges of the cells and large subsidence in the middle of the cells, with same spatial dimensions and structure sizes. These are typical pattern of the PBL which remain in conformity with typical LES studies. At $250 \mathrm{~m}$ altitude, maximum updrafts and downdrafts reach up to $8 \mathrm{~m} \cdot \mathrm{s}^{-1}$ and $-6 \mathrm{~m} \cdot \mathrm{s}^{-1}$ in both models, with slightly higher values over few grid points in SwRI results. At $2 \mathrm{~km}$ altitude, where updrafts are more vigorous, the differences between both results are more pronounced. LMD LES predict maximum updrafts values of $8 \mathrm{~m} \cdot \mathrm{s}^{-1}$ while SwRI LES results show values twice higher, around $15 \mathrm{~m} \cdot \mathrm{s}^{-1}$ (see Section 6). Because of mass conservation, downdrafts are also found to be more vigorous in the SwRI LES than in the LMD LES.

Figure 6 and Figure 7 show horizontal sections of horizontal wind amplitudes at local time 11:00, at about 5 and $250 \mathrm{~m}$ above the surface, in the case of an ambient wind of 0 and $15 \mathrm{~m} \cdot \mathrm{s}^{-1}$ respectively.

In the case without ambient wind, horizontal wind structures are similar in both models and typically show gusts in all directions related to the convective cells in the PBL. However, it can be noticed that the variability at very small scale (i.e. a few grid points apart) is much higher in SwRI results than in LMD results. This higher small-scale variability appears in all SwRI simulations and may be related to the quantitative discrepancies discussed in Section 6. Here, maximum horizontal wind amplitudes at $5 \mathrm{~m}$ above surface are found to be in the range 6-8 m.s $\mathrm{s}^{-1}$ in both LMD and SwRI LES, although SwRI results also show maximum values at $12 \mathrm{~m} . \mathrm{s}^{-1}$ over a few grid points. At $250 \mathrm{~m}$ above surface, horizontal winds reach $6 \mathrm{~m} . \mathrm{s}^{-1}$ in both models ( $9 \mathrm{~m} \cdot \mathrm{s}^{-1}$ over a few grid points in the SwRI model). 
Geosci. Model Dev. Discuss., doi:10.5194/gmd-2016-241, 2016

Manuscript under review for journal Geosci. Model Dev.

Published: 16 November 2016

(c) Author(s) 2016. CC-BY 3.0 License.

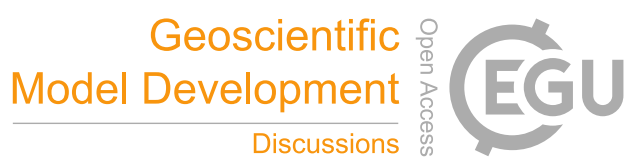

(c) (i)

When a sufficiently strong ambient wind is added (typically more than $10 \mathrm{~m} \cdot \mathrm{s}^{-1}$ ), it distorts the organization in polygonal cells and forces the gusts to propagate in the same direction, as shown by Figure 7. In this case, LMD wind amplitudes are found to be larger than SwRI values, especially $250 \mathrm{~m}$ above the surface, although the wind structures remain similar in both LES. Maximum values for horizontal wind are $16-18 \mathrm{~m} \cdot \mathrm{s}^{-1}$ in both LES.

5 This difference in altitude is highlighted by Figure 8, showing the mean profile of horizontal winds in both models between 11:00 and 12:00. SwRI results show weaker horizontal winds than LMD results in the whole PBL. Although these differences could be related to the different intensity of the convection, they may also be related to the different scheme of near-surface stability. The large differences encountered in the first hundreds of meters reinforce this possibility.

\subsection{Comparisons of PBL diagnostics}

LES results compared in this section are the PBL depth, the turbulent kinetic energy (TKE) and the maximum updrafts and downdrafts within the PBL, which are key characteristics of the convection inside the Martian PBL. The PBL depth is directly and positively correlated to the intensity of its dynamics while the TKE is a measure of turbulence intensity and is directly related to the transport of heat and momentum through the PBL. An increase of TKE denotes a more turbulent PBL. Updrafts and downdrafts also enable to compare the intensity of the PBL turbulence in both models. Table 3 and Table 4 summarize the results.

\subsubsection{Planetary boundary layer height}

Figure 10 shows that the daytime PBL depth grows faster and reaches a higher vertical extent in the SwRI LES than in the LMD LES. By the end of the afternoon, the PBL depth reaches $7.5 \mathrm{~km}$ (SwRI) and $4.8 \mathrm{~km}$ (LMD) without ambient wind and slightly more in windy conditions. These results confirm that the convection in the SwRI LES is more vigorous. In fact, the maximum PBL depth obtained in the SwRI LES is close to the highest values that could be found on Mars and measured through radio-occultations, which are about 8-10 km (Spiga et al., 2010).

\subsubsection{Turbulent kinetic energy}

The differences in the vertical extent of PBL mixing between both LES can also be inferred from the variations of (resolved) TKE, as shown by Figure 11. Although the convective activity rapidly declines at same local time 17:00 and the maximum

TKE values occur around same local times 13:00-14:00 in both models, larger TKE values are found in the SwRI LES, in consistency with previous results,. Without ambient wind, the maximum TKE in the PBL reaches $12 \mathrm{~m}^{2} . \mathrm{s}^{-2}$ around $1.5 \mathrm{~km}$ altitude in LMD results, while it reaches about $21 \mathrm{~m}^{2} . \mathrm{s}^{-2}$ around $3.5 \mathrm{~km}$ altitude in SwRI results, a factor of two more intense. Similar differences are found in the LES with windy condition. 
Geosci. Model Dev. Discuss., doi:10.5194/gmd-2016-241, 2016

Manuscript under review for journal Geosci. Model Dev.

Published: 16 November 2016

(c) Author(s) 2016. CC-BY 3.0 License.

Table 3. Maximum PBL diagnostics values from the LMD and SwRI LES without ambient wind

\begin{tabular}{|c|c|c|c|}
\hline LES without ambient wind & LMD & SwRI & Difference (\%) \\
PBL Height $(\mathrm{km})$ & 4.8 & 7.5 & 56 \\
Turbulent Heat Flux $\left(\mathrm{K} . \mathrm{m} . \mathrm{s}^{-1}\right)$ & $<1.25$ & $<3.2$ & 156 \\
Turbulent Kinetic Energy $\left(\mathrm{m}^{2} . \mathrm{s}^{-2}\right)$ & $<12$ & $<21$ & 75 \\
Maximum Updraft Speed $\left(\mathrm{m} . \mathrm{s}^{-1}\right)$ & $<15$ & $<24$ & 60 \\
Maximum Downdraft Speed $\left({\left.\mathrm{m} . \mathrm{s}^{-1}\right)}<8\right.$ & $<12$ & 50 \\
\hline
\end{tabular}

\subsubsection{Maximum speed for convective updrafts}

In line with previous results, Figure 12 shows that maximum updraft speeds obtained from SwRI LES are higher than those from LMD LES, with a ratio of about 1.5-1.8, all over the mixing layer depth between local times 11:00 and 17:00. In LES without ambient wind, maximum speeds reach 13-15 m.s ${ }^{-1}$ in LMD results around local times 12:00 - 14:00 between altitudes

52 to $4 \mathrm{~km}$ while they reach 20-24 m.s ${ }^{-1}$ in SwRI results between altitudes 2 to $6 \mathrm{~km}$ at same local times. In windy conditions, maximum updraft speeds in both LMD and SwRI LES remain in similar ranges.

\subsubsection{Maximum speed for convective downdrafts}

In both LES, maximum updraft speeds (Figure 12) are in comparison larger by a factor 2 than maximum downdraft speeds (Figure 13). This is a consequence of the organization of turbulence in cells with narrow updrafts and broader downdrafts. Both LES predict maximum downdraft between local times 13:00 and 15:00. Without ambient wind, downdraft up to 8 m.s ${ }^{-1}$ are predicted by the LMD LES from $200 \mathrm{~m}$ to $5 \mathrm{~km}$ above the surface while the SwRI LES predicts values up to $12 \mathrm{~m} \cdot \mathrm{s}^{-1}$. In the LES with ambient wind, these values slightly increase to $9 \mathrm{~m} \cdot \mathrm{s}^{-1}$ and $15 \mathrm{~m} \cdot \mathrm{s}^{-1}$ respectively.

\subsubsection{Distributions of vertical wind speeds}

Figure 14 and Figure 15 show the distribution of vertical wind speeds obtained between local times 13:00-14:00 and altitudes 250-5000 m, for both LES without and with ambient wind respectively. In the windless case, 95\% of vertical wind speeds are in the $[-6,6] \mathrm{m} \cdot \mathrm{s}^{-1}$ range for LMD and $[-9,9] \mathrm{m} . \mathrm{s}^{-1}$ for SwRI. In the windy case, 95\% of vertical wind speeds are in the [-7,7] $\mathrm{m} . \mathrm{s}^{-1}$ range for LMD, and $[-11,11] \mathrm{m} . \mathrm{s}^{-1}$ for SwRI. Therefore, the strongest vertical winds represent a very low probability. As an example, in the SwRI LES, both the maximum downdraft value of $11 \mathrm{~m} \cdot \mathrm{s}^{-1}$ and the maximum updraft value of $28 \mathrm{~m} . \mathrm{s}^{-1}$ represent less than $0.01 \%$ of all values.

\section{Sensitivity simulations}

This section presents a sensitivity study of the Martian daytime PBL properties in the LMD LES model to dust loading, surface albedo, ambient wind and subgrid scale diffusion coefficient, using the same reference settings as described in Section 3.1, 
Geosci. Model Dev. Discuss., doi:10.5194/gmd-2016-241, 2016

Manuscript under review for journal Geosci. Model Dev.

Published: 16 November 2016

(c) Author(s) 2016. CC-BY 3.0 License.

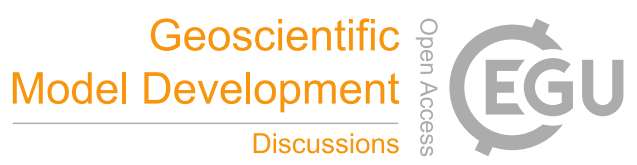

(c) (i)

Table 4. Maximum PBL diagnostics values from the LMD and SwRI LES with $15 \mathrm{~m} \cdot \mathrm{s}^{-1}$ ambient wind

\begin{tabular}{|c|c|c|c|}
\hline LES with $15 \mathrm{~m} . \mathrm{s}^{-1}$ ambient wind & LMD & SwRI & Difference (\%) \\
PBL Height $(\mathrm{km})$ & 5.3 & 8.1 & 53 \\
Turbulent Heat Flux $\left(\mathrm{K} . \mathrm{m} . \mathrm{s}^{-1}\right)$ & $<1.7$ & $<3.4$ & 100 \\
Turbulent Kinetic Energy $\left(\mathrm{m}^{2} . \mathrm{s}^{-2}\right)$ & $<15$ & $<34$ & 126 \\
Maximum Updraft Speed $\left(\mathrm{m} . \mathrm{s}^{-1}\right)$ & $<15$ & $<22$ & 46 \\
Maximum Downdraft Speed $\left(\mathrm{m} . \mathrm{s}^{-1}\right)$ & $<9$ & $<15$ & 60 \\
\hline
\end{tabular}

Table 4. Maximum PBL diagnostics values from the LMD and SwRI LES with $15 \mathrm{~ms}$-1 ambient wind

without ambient wind. This enables to better understand the mechanisms and the role of forcing in the Martian PBL, and allows further investigation of the discrepancies observed between SwRI and LMD LES results. Furthermore, it deserves an entire section, since it has seldom been detailed in the literature.

\subsection{Sensitivity to subgrid scale diffusion}

5 Can a difference in the small-scale diffusion schemes in both models be related to the difference of values of PBL depth, maximum TKE and vertical wind speeds detailed in Section 4.2.1? To attempt to answer this question, the LMD LES model has been run with different subgrid scale diffusion coefficients (or mixing coefficient). Tested with much lower values than the typical one used (0.15 at LMD, decreased by a factor up to $10^{6}$ ), the PBL diagnostics remain similar with a decrease of PBL height of less than $5 \%$ in the afternoon. Same conclusions apply when analyzing the maximum TKE or wind speeds, confirming that the small-scale mixing coefficient has a negligible impact on the development of the convective PBL in the daytime.

\subsection{Sensitivity to dust opacity}

LES have been performed using distinct dust optical depths of 0.2 (reference), 0.6, 1 and 3. Comparing LES predictions in those three cases reveals dramatic differences in the strength of the boundary layer convection. Figure 16 shows how the daytime evolution of boundary layer depth is influenced by dustiness in the Martian atmosphere. Firstly, the mixing layer is of significantly lower vertical extent for higher dust opacities (which is true during the whole day). At local time 14:00, boundary layer depths are respectively $3.8,3,2.5,1.7 \mathrm{~km}$ for dust loadings $0.2,0.6,1,3$. This behaviour originates from dust absorption of solar radiation in the visible leading to decrease in surface temperature. Moreover, stability in the lowest layers of the atmosphere is enhanced by dust heating, which leads to a less vigorous boundary layer turbulent convection.

Secondly, the PBL is collapsing earlier in the afternoon when dust opacity increases: while the PBL depth is still maximum at local time 17:00 in a clear atmosphere, it starts to slightly decay for a dust opacity at 0.6 and more distinctively decrease for an opacity at 1 (the maximum vertical extent in this case is attained around local time 15:30). The most extreme case (dust opacity at 3) shows a very limited growth of the convective boundary layer, which peaks at the very low value (with respect to 
Geosci. Model Dev. Discuss., doi:10.5194/gmd-2016-241, 2016

Manuscript under review for journal Geosci. Model Dev.

Published: 16 November 2016

(c) Author(s) 2016. CC-BY 3.0 License.

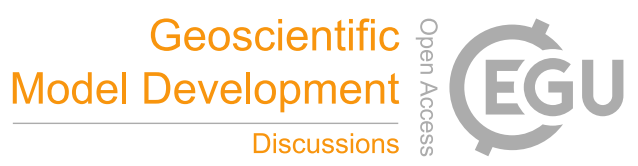

(c) (i)

Martian standards) of $1.7 \mathrm{~km}$ between local times 13:00 and 14:00, before a rapid collapse of the turbulent convection occurs at local time 14:00-14:30.

Both the limitation of convective activity and the displacement of its maximum towards earlier afternoon associated with an increase in dust optical depth can also be assessed by the comparison of maximum (resolved) TKE shown on Figure 17. Differences in TKE between the clear and extremely dusty cases are about one order-of-magnitude - even differences between the opacity 0.2 and 1 are significant (50 to $60 \%$ decrease). It is interesting to note that, in theory, dust radiative heating by absorption in the visible (plus a smaller contribution in the infrared) should cause TKE and updraft speeds to increase with dust opacity. Present LES results with complete radiative transfer show this effect does not significantly compensate the aforementioned influence of dust loading on surface temperature and atmospheric stability. Overall, the dustiness of the Martian atmosphere strongly determines the strength of boundary layer convection and this has important consequences on conditions for EDL systems as ExoMars landing between 14:00 and 16:00. This is exemplified by maximum vertical wind speeds (not shown). Maximum updraft and downdraft values throughout the whole day vary dramatically with dust opacity: updrafts of $15,12,10,4 \mathrm{~m} . \mathrm{s}^{-1}$ and downdrafts of $-9,-7,-5,-2 \mathrm{~m} . \mathrm{s}^{-1}$ are predicted by LMD LES for dust opacities $0.2,0.6,1$ and 3. Again, convection for an opacity at 3 is severely limited. Vertical winds are lower at 16:00 than at 14:00 in all cases, but the differences are more prominent between the two local times when more dust is suspended in the Martian atmosphere.

Finally, it is important to note that if the dust opacity values follow a geometric progression which implies a linear increase in atmospheric heating, variations of PBL depth, TKE and maximum winds with dust opacity are not linear. The sensitivity of PBL turbulence to dust opacity is a complex combination of dust influencing surface temperature, atmospheric stability and maximum turbulent heat flux as well as turbulent motions adjusting to those various modified forcings. Only LES employing full radiative transfer can address this complexity.

\subsection{Sensitivity to surface albedo}

In order to assess the sensitivity of the PBL to surface conditions, the LMD LES has been tested with surface albedo value of 0.1, 0.21 (reference), 0.4 and 0.6. A value of 0.1 is extreme, although not unrealistic, and causes surface temperatures to be significantly warmer, hence boundary layer convection to be more vigorous, as shown by Figure 18 and Figure 19. A lower albedo not only cause the sensible heat flux to be larger, but also the infrared radiative flux emitted by the surface and absorbed by $\mathrm{CO}_{2}$ and dust in the lowermost atmospheric layers to be larger. The PBL depth predicted by LES is about $20 \%$ higher for the 0.1 albedo case, and 35\% lower for the 0.4 case, compared to the 0.21 case. Similar conclusions apply for the maximum TKE predicted. The PBL convection on a more reflective surface is very limited, with a height of $1.5 \mathrm{~km}$ for an albedo up to 0.6 .

\subsection{Sensitivity to ambient wind}

The sensitivity of the PBL to the ambient wind is addressed by running the LMD LES with 0, 15 (both reference runs) and $25 \mathrm{~m} \cdot \mathrm{s}^{-1}$ ambient wind. In the afternoon, the wind enhances convection by increasing the surface-atmosphere heat and momentum transfer in the surface layer. Larger wind speeds thus yield higher values for turbulent heat flux, and higher values of 
Geosci. Model Dev. Discuss., doi:10.5194/gmd-2016-241, 2016

Manuscript under review for journal Geosci. Model Dev.

Published: 16 November 2016

(c) Author(s) 2016. CC-BY 3.0 License.

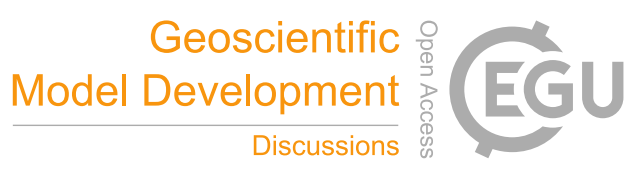

TKE (according to the TKE equation). Figure 21 shows that the PBL in windy conditions is especially vigorous between local times 12:00 and 15:30. In addition, the boundary layer convection appears to start earlier in the morning in windy conditions. The maximum TKE predicted by LES in the afternoon is about $20 \%$ higher for the $15 \mathrm{~m} . \mathrm{s}^{-1}$ case ( $40 \%$ for the $25 \mathrm{~m} . \mathrm{s}^{-1}$ case) compared to the no-wind case. In such conditions, the maximum PBL depth is higher by about $500 \mathrm{~m}(10 \%)$ in the $15 \mathrm{~m} . \mathrm{s}^{-1}$

5 case and $700 \mathrm{~m}(15 \%)$ in the $25 \mathrm{~m} \cdot \mathrm{s}^{-1}$ case, as shown by Figure 20. Quantitative estimates about maximum vertical winds have to be raised to about $10 \%$ and $15 \%$ in the $15 \mathrm{~m} . \mathrm{s}^{-1}$ and $25 \mathrm{~m} . \mathrm{s}^{-1}$ ambient wind cases respectively, compared to the no-wind estimates (figure not shown).

\section{Discussion}

The steps of the intercomparison between the LMD and SwRI LES models can be summarized as follows: LES have been performed at ExoMars landing site and date using settings as similar as possible. A tuning of the LMD radiative transfer routine has been necessary to ensure a similar radiative response of both LMD and SwRI models to same forcings. This tuning involved slight changes of dust properties (extinction and brightness) and surface thermal inertia (increased from 238 tiu to 300 tiu in the LMD LES), essential to obtain similar daytime surface temperatures in both LES and thus to similarly force the turbulence within the PBL.

The comparison of LES shows similar qualitative results (vertical wind organized into polygonal cells, horizontal gusts) but different quantitative results. SwRI results show values of heat flux, kinetic energy, updraft or downdraft speeds which are more dispersed, with maximum values higher than LMD results with a ratio between 1.5 and 2, as summarized by Table 3 and Table 4. This leads to an almost twice more vigorous PBL in the SwRI LES than in the LMD PBL, even though the maximum values only represent a very small fraction of the domain. Results remain similar with or without ambient wind.

It is important to note that all the results and values obtained from both models remain realistic (with the caveat in mind that no measurements of vertical wind in the Martian convective boundary layer are available from previous missions). The LMD LES showed good agreement with other LMD LES performed in the past in conditions close to the ExoMars landing site, with typical updrafts and downdrafts speed around 8-12 m.s ${ }^{-1}$, and with radio-occultation measurements (Spiga et al., 2010). The boundary layer depths predicted by the SwRI LES model, although clearly in the upper range, are still consistent with those measurements.

The discrepancies observed between both LES can not be explained by differences in boundary conditions or radiative forcing, which are similar in both models (less than $1 \mathrm{~K}$ difference). It has been found in Section 4.2 that SwRI results exhibit a higher variability at a very small scale than LMD results. This could stem from different assumptions in the subgrid-scale diffusion schemes adopted in both LES. On the one hand, the SwRI LES reflects a much weaker subgrid-scale diffusion than the LMD LES, which would put the SwRI LES at greater risk to overestimate maximum vertical winds ("noisy" turbulent signals). On the other hand, the LMD LES appears to have a subgrid-scale diffusion which efficiently removes the accumulation of energy at grid point scale, although the possibility still exists that this subgrid-scale diffusion might be too strong, yielding underestimated vertical winds. We tested different subgrid scale diffusion coefficients with the LMD LES model but these 
Geosci. Model Dev. Discuss., doi:10.5194/gmd-2016-241, 2016

Manuscript under review for journal Geosci. Model Dev.

Published: 16 November 2016

(c) Author(s) 2016. CC-BY 3.0 License.

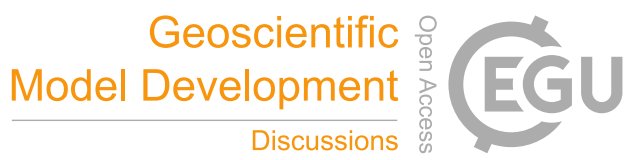

(c) (i)

changes did not significantly affect the PBL. Consequently, it is plausible that the differences observed between both models lie deeper in the assumptions of their small-scale diffusion schemes, or in other dynamic parts of the models (e.g. the distinct discretization of the hydrodynamical equations). This remains to be explored further in the respective models. Finally, as suggested in Section 4.2.1, differences in the PBL near-surface scheme used in both models could also impact the LES results.

5 Results in Section 5 show that the PBL can be strongly affected by large changes of dust loading and surface conditions. In contrast, although the influence of ambient wind on the Martian PBL turbulence is a significant component to be taken into account for EDL studies, results with ambient wind will not change drastically compared to no-wind simulations (here the Martian situation is quite different from the Earth due to the radiative control of the boundary layer). Comparing windy simulations (Figure 20, Figure 21) with extreme soil simulations (Figure 18, Figure 19) or with dusty simulations (Figure 16, Figure 17) shows that windy conditions represent a secondary influence of Martian PBL convection and is likely to be overcome by changes in the primary forcing of the Martian PBL, that is, radiative control. Turbulent convective activity is enhanced in windy conditions, but this is overwhelmed by the strong suppression of boundary layer growth caused by very dusty conditions.

The conclusions of the intercomparison campaign presented in this paper do not prevent LES from being relevant tools to study the PBL turbulence on Mars and to provide constraints to assess atmospheric hazards encountered by future landing systems, provided caution is exerted along the quantitative lines drawn by the estimates in this paper. Above all, improving the diagnostics provided by Martian LES will require more complete observations of the Martian PBL turbulence in future in situ missions to Mars.

\section{Data availability}

The SwRI and LMD files, figure data or any other source data of this paper are freely available upon request by contacting T.B. or A.S. (tanguy.bertrand@1md.jussieu.fr, spiga@1md.jussieu.fr).

Author contributions. Author contribution

T.B. prepared and performed the LMD simulations, S.R performed the SwRI simulations. Both T.B. and A.S contributed to the writing of the manuscript.

\section{Competing interests. Competing interests}

The authors declare no competing financial interests. 
Geosci. Model Dev. Discuss., doi:10.5194/gmd-2016-241, 2016

Manuscript under review for journal Geosci. Model Dev.

Published: 16 November 2016

(c) Author(s) 2016. CC-BY 3.0 License.

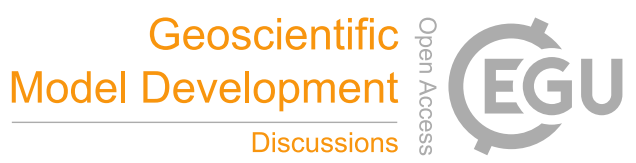

(c) (i)

\section{References}

Barth, E. and Rafkin, S.: TRAMS: A new dynamic cloud model for Titan's methane clouds, Geophys. Res. Lett., 34, L03 $203,2007$.

Colaïtis, A., Spiga, A., Hourdin, F., Rio, C., Forget, F., and Millour, E.: A thermal plume model for the Martian convective boundary layer, Journal of Geophysical Research (Planets), 118, 1468-1487, doi:10.1002/jgre.20104, 2013.

Deardorff, J. W.: Stratocumulus-capped mixed layers derived from a three-dimensional model, Boundary-Layer Meteorology, 18, 495-527, doi:10.1007/BF00119502, 1980.

Fenton, L. and Michaels, T. I.: Characterizing the sensitivity of daytime turbulent activity on Mars with the MRAMS LES: Early results, International Journal of Mars Science and Exploration, 5, 159-171, doi:10.1555/mars.2010.0007, 2010.

Forget, F., Hourdin, F., Fournier, R., Hourdin, C., Talagrand, O., Collins, M., Lewis, S. R., Read, P. L., and Huot., J.-P.: Improved general circulation models of the Martian atmosphere from the surface to above 80 km, J. Geophys. Res., 104, 24,155-24,176, 1999.

Gheynani, B. T. and Taylor, P. A.: Large Eddy Simulation of typical dust devil like vortices in highly convective Martian boundary layers at the Phoenix lander site, pss, 59, 43-50, doi:10.1016/j.pss.2010.10.011, 2011.

Gierasch, P. J. and Goody, R. M.: A study of the thermal and dynamical structure of the Martian lower atmosphere, Planet. Space Sci., 16, 615-646, 1968.

Gierasch, P. J. and Goody, R. M.: The effect of dust on the temperature of the Martian atmosphere., Journal of Atmospheric Sciences, 29, 400-402, doi:10.1175/1520-0469(1972)029<0400:TEODOT>2.0.CO;2, 1972.

Haberle, R. M., Pollack, J. B., Barnes, J. R., Zurek, R. W., Leovy, C. B., Murphy, J. R., Lee, H., and Schaeffer, J.: Mars Atmospheric Dynamics as Simulated by the NASA/Ames General Circulation model, 1, The zonal-Mean Circulation, J. Geophys. Res., 98, 3093-3124, 1993.

Hinson, D. P., Pätzold, M., Tellmann, S., Häusler, B., and Tyler, G. L.: The depth of the convective boundary layer on Mars, Icarus, 198, 57-66, doi:10.1016/j.icarus.2008.07.003, 2008.

Imamura, T., Higuchi, T., Maejima, Y., Takagi, M., Sugimoto, N., Ikeda, K., and Ando, H.: Inverse insolation dependence of Venus cloud level convection, Icarus, 228, 181-188, doi:10.1016/j.icarus.2013.10.012, 2014.

Kass, D. M., Schofield, J. T., Michaels, T. I., Rafkin, S. C. R., Richardson, M. I., and Toigo, A. D.: Analysis of atmospheric mesoscale models for entry, descent, and landing, Journal of Geophysical Research (Planets), 108, 8090-+, doi:10.1029/2003JE002065, 2003.

Lefèvre, M., Spiga, A., and Lebonnois, S.: Three-dimensional turbulence-resolving modeling of the Venusian convective cloud layer and induced gravity waves, Journal of Geophysical Research, Planets (submitted), 2016.

Lilly, D. K.: On the numerical simulation of buoyant convection, Tellus, 14, 148-172, 1962.

Madeleine, J.-B., Forget, F., Millour, E., Montabone, L., and Wolff, M. J.: Revisiting the radiative impact of dust on Mars using the LMD Global Climate Model, Journal of Geophysical Research (Planets), 116, E11010, doi:10.1029/2011JE003855, 2011.

Malin, M. C. and Edgett, K. S.: Mars Global Surveyor Mars Orbiter Camera: Interplanetary cruise through primary mission, J. Geophys. Res., 106, 23 429-23 570, doi:10.1029/2000JE001455, 2001.

Mason, P.: Large-Eddy Simulation of the Convective Atmospheric Boundary Layer, Journal of the Atmospheric Sciences, 46, 1492-1516, 1989.

Michaels, T. I. and Rafkin, S. C. R.: Large eddy simulation of atmospheric convection on Mars, Q. J. R. Meteorol. Soc., 130, 1251-1274, doi:10.1256/qj.02.169, 2004.

Moeng, C., Dudhia, J., Klemp, J., and Sullivan, P.: Examining Two-Way Grid Nesting for Large Eddy Simulation of the PBL Using the WRF Model, Monthly Weather Review, 135, 2295-2311, 2007. 
Geosci. Model Dev. Discuss., doi:10.5194/gmd-2016-241, 2016

Manuscript under review for journal Geosci. Model Dev.

Published: 16 November 2016

(c) Author(s) 2016. CC-BY 3.0 License.

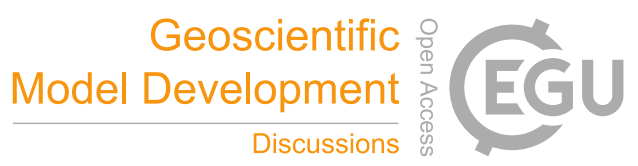

(c) (i)

Montabone, L., Forget, F., Millour, E., Wilson, R. J., Lewis, S. R., Cantor, B., Kass, D., Kleinböhl, A., Lemmon, M. T., Smith, M. D., and Wolff, M. J.: Eight-year climatology of dust optical depth on Mars, Icarus, 251, 65-95, doi:10.1016/j.icarus.2014.12.034, 2015.

Mulholland, D. P., Spiga, A., Listowski, C., and Read, P. L.: An assessment of the impact of local processes on dust lifting in martian climate models, Icarus, 252, 212-227, doi:10.1016/j.icarus.2015.01.017, 2015.

5 Ockert-Bell, M. E., Bell III, J. F., McKay, C., Pollack, J., and Forget, F.: Absorption and scattering properties of the Martian dust in the solar wavelengths, J. Geophys. Res., 102, 9039-9050, 1997.

Pielke, R., Cotton, W., Walko, R., Trembaek, C., Lyons, W., Grasso, L., Nieholls, M., Moran, M., Wesley, D., Lee, T., et al.: A Comprehensive Meteorological Modeling System-RAMS, Meteorol. Atmos. Phys, 49, 69-91, 1992.

Pollack, J. B., Haberle, R. M., Schaeffer, J., and Lee, H.: Simulations of the general circulation of the Martian atmosphere, 1, Polar processes,

J. Geophys. Res., 95, 1447-1473, 1990.

Rafkin, S. C. R. and Michaels, T. I.: Meteorological predictions for 2003 Mars Exploration Rover high-priority landing sites, Journal of Geophysical Research (Planets), 108, 8091, doi:10.1029/2002JE002027, 2003.

Rafkin, S. C. R., Haberle, R. M., and Michaels, T. I.: The Mars Regional Atmospheric Modeling System: Model Description and Selected Simulations, Icarus, 151, 228-256, 2001.

15 Richardson, M. I., Toigo, A. D., and Newman, C. E.: PlanetWRF: A general purpose, local to global numerical model for planetary atmospheric and climate dynamics, J. Geophys. Res., 112, doi:10.1029/2005JE002636, 2007.

Savijärvi, H. and Kauhanen, J.: Surface and boundary-layer modelling for the Mars Exploration Rover sites, Quarterly Journal of the Royal Meteorological Society, 134, 635-641, doi:10.1002/qj.232, 2008.

Schofield, J. T., Crisp, D., Barnes, J. R., Haberle, R. M., Magalhaães, J. A., Murphy, J. R., Seiff, A., Larsen, S., and Wilson, G.: The Mars Pathfinder Atmospheric Structure Investigation/Meteorology (ASI/MET) experiment, Science, 278, 1752-1757, 1997.

Skamarock, W. C. and Klemp, J. B.: A time-split nonhydrostatic atmospheric model for weather research and forecasting applications, Journal of Computational Physics, 227, 3465-3485, doi:10.1016/j.jcp.2007.01.037, 2008.

Smith, M. D., Wolff, M. J., Spanovich, N., Ghosh, A., Banfield, D., Christensen, P. R., Landis, G. A., and Squyres, S. W.: One Martian year of atmospheric observations using MER Mini-TES, Journal of Geophysical Research (Planets), 111, 12-+, doi:10.1029/2006JE002770, 2006.

Spiga, A.: Elements of comparison between Martian and terrestrial mesoscale meteorological phenomena: Katabatic winds and boundary layer convection, Planetary and Space Science, 59, 915-922, doi:10.1016/j.pss.2010.04.025, 2011.

Spiga, A. and Forget, F.: A new model to simulate the Martian mesoscale and microscale atmospheric circulation: Validation and first results, Journal of Geophysical Research (Planets), 114, E02 009, doi:10.1029/2008JE003242, 2009.

Spiga, A., Forget, F., Lewis, S. R., and Hinson, D. P.: Structure and Dynamics of the Convective Boundary Layer on Mars as Inferred from Large-Eddy Simulations and Remote-Sensing Measurements, Quarterly Journal of the Royal Meteorological Society, 136, 414-428, doi:10.1002/qj.563, 2010.

Spiga, A., Barth, E., Gu, Z., Hoffmann, F., Ito, J., Jemmett-Smith, B., Ito, J., Klose, M., Nishizawa, S., Raasch, S., Rafkin, S., Takemi, T., Tyler, D., and Wei, W.: Large-Eddy Simulations of dust devils and convective vortices, Space Science Reviews (accepted), 2016.

Sutton, J. L., Leovy, C. B., and Tillman, J. E.: Diurnal variations of the Martian surface layer meteorological parameters during the first 45 sols at two Viking lander sites, J. Atmos. Sci., 35, 2346-2355, 1978.

Thomas, P. and Gierasch, P. J.: Dust devils on Mars, Science, 230, 175-177, 1985. 
Geosci. Model Dev. Discuss., doi:10.5194/gmd-2016-241, 2016

Manuscript under review for journal Geosci. Model Dev.

Published: 16 November 2016

(c) Author(s) 2016. CC-BY 3.0 License.

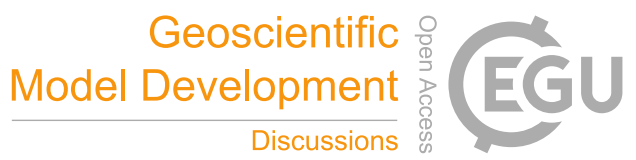

(c) (i)

Toigo, A. D. and Richardson, M. I.: Meteorology of proposed Mars Exploration Rover landing sites, J. Geophys. Res., 108, 8092-+, doi:10.1029/2003JE002064, 2003.

Tyler, D., Barnes, J. R., and Skyllingstad, E. D.: Mesoscale and large-eddy simulation model studies of the Martian atmosphere in support of Phoenix, Journal of Geophysical Research (Planets), 113, 0-+, doi:10.1029/2007JE003012, 2008.

5 Whiteway, J. A., Komguem, L., Dickinson, C., Cook, C., Illnicki, M., Seabrook, J., Popovici, V., Duck, T. J., Davy, R., Taylor, P. A., Pathak, J., Fisher, D., Carswell, A. I., Daly, M., Hipkin, V., Zent, A. P., Hecht, M. H., Wood, S. E., Tamppari, L. K., Renno, N., Moores, J. E., Lemmon, M. T., Daerden, F., and Smith, P. H.: Mars Water-Ice Clouds and Precipitation, Science, 325, 68-, doi:10.1126/science.1172344, 2009.

Wolff, M. J., Smith, M. D., Clancy, R. T., Arvidson, R., Kahre, M., Seelos, F., Murchie, S., and Savijärvi, H.: Wavelength dependence of dust aerosol single scattering albedo as observed by the Compact Reconnaissance Imaging Spectrometer, Journal of Geophysical Research (Planets), 114, 0-+, doi:10.1029/2009JE003350, 2009. 
Geosci. Model Dev. Discuss., doi:10.5194/gmd-2016-241, 2016

Manuscript under review for journal Geosci. Model Dev.

Published: 16 November 2016

(c) Author(s) 2016. CC-BY 3.0 License.

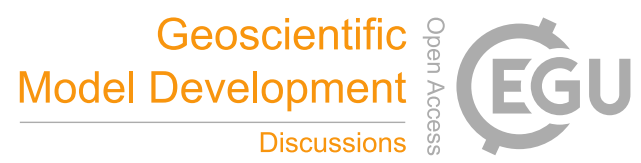

(c) (1)
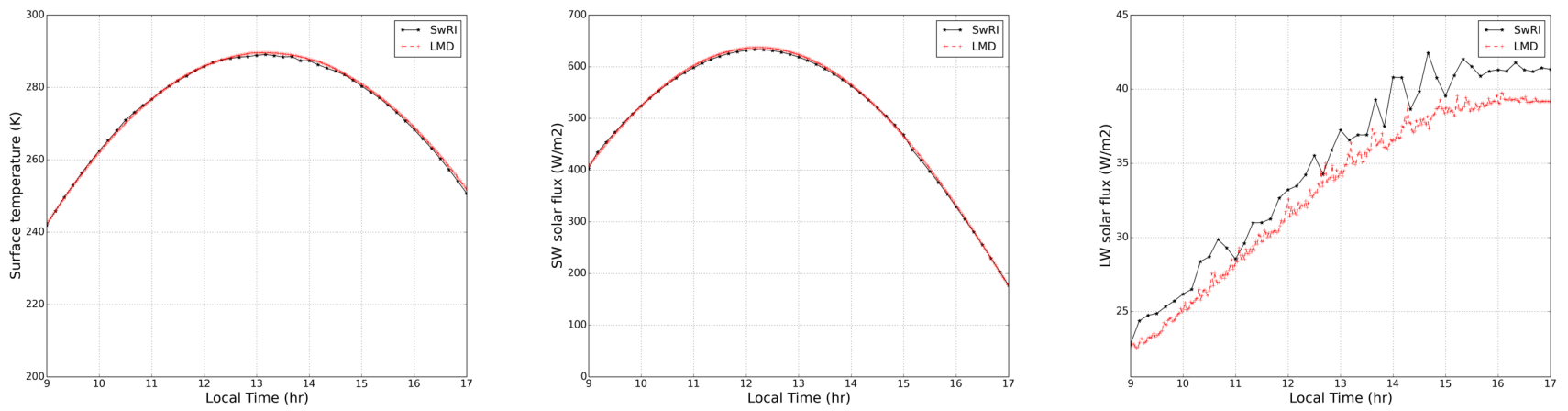

Figure 5. Initial surface conditions in SwRI (black) and LMD (red) LES models. Left are the surface temperatures, middle is the incident short wave solar flux and right is the incident long wave solar flux. 
Geosci. Model Dev. Discuss., doi:10.5194/gmd-2016-241, 2016 Manuscript under review for journal Geosci. Model Dev.

Published: 16 November 2016

(c) Author(s) 2016. CC-BY 3.0 License.

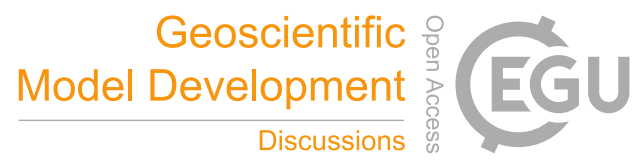

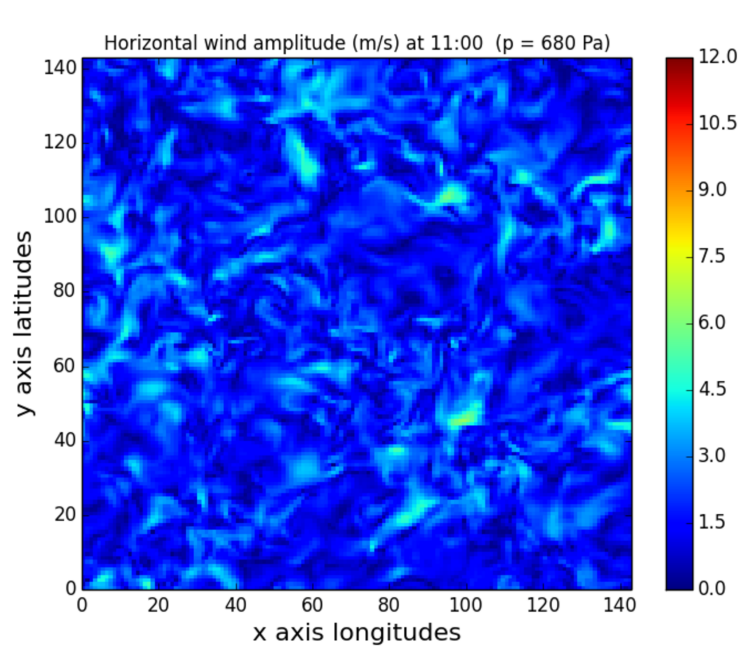

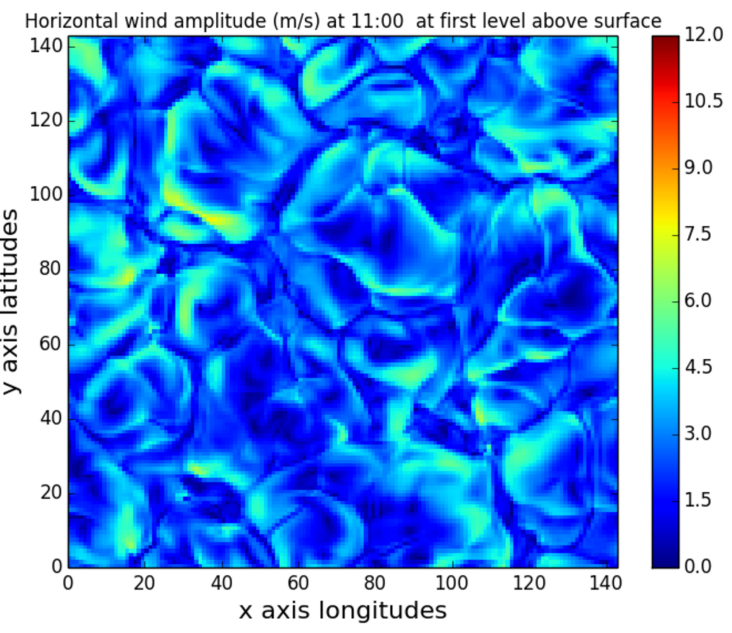

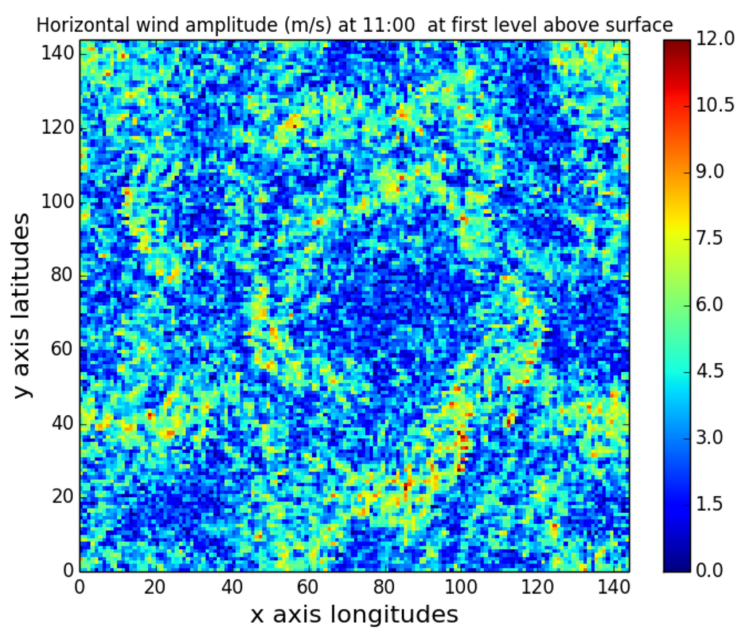

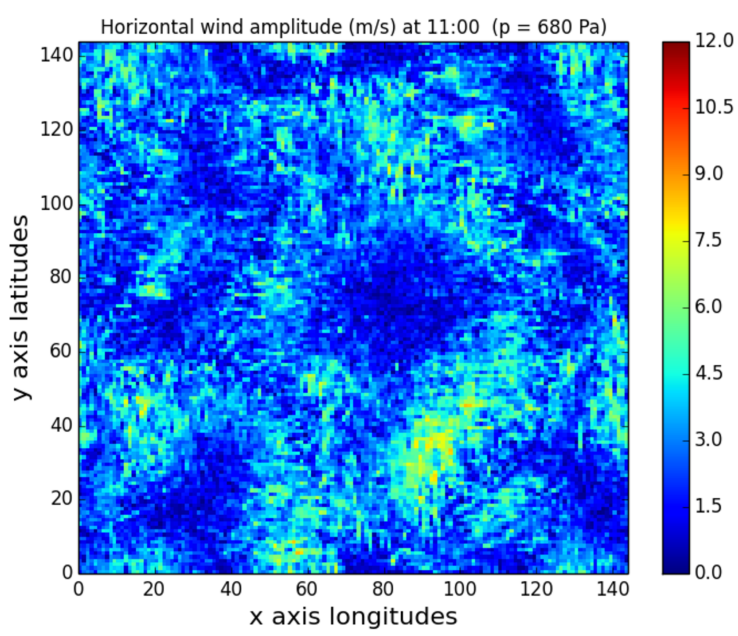

Figure 6. LMD (left) and SwRI (right) horizontal section of horizontal wind amplitudes at first level above surface (top) and at about $250 \mathrm{~m}$ above surface (bottom), at local time 11:00. Simulation without ambient wind 
Geosci. Model Dev. Discuss., doi:10.5194/gmd-2016-241, 2016 Manuscript under review for journal Geosci. Model Dev.

Published: 16 November 2016

(c) Author(s) 2016. CC-BY 3.0 License.

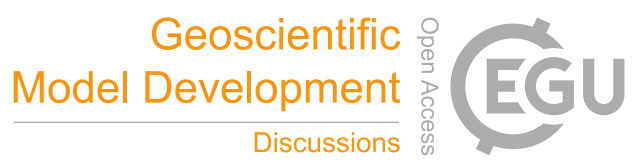

Discussions
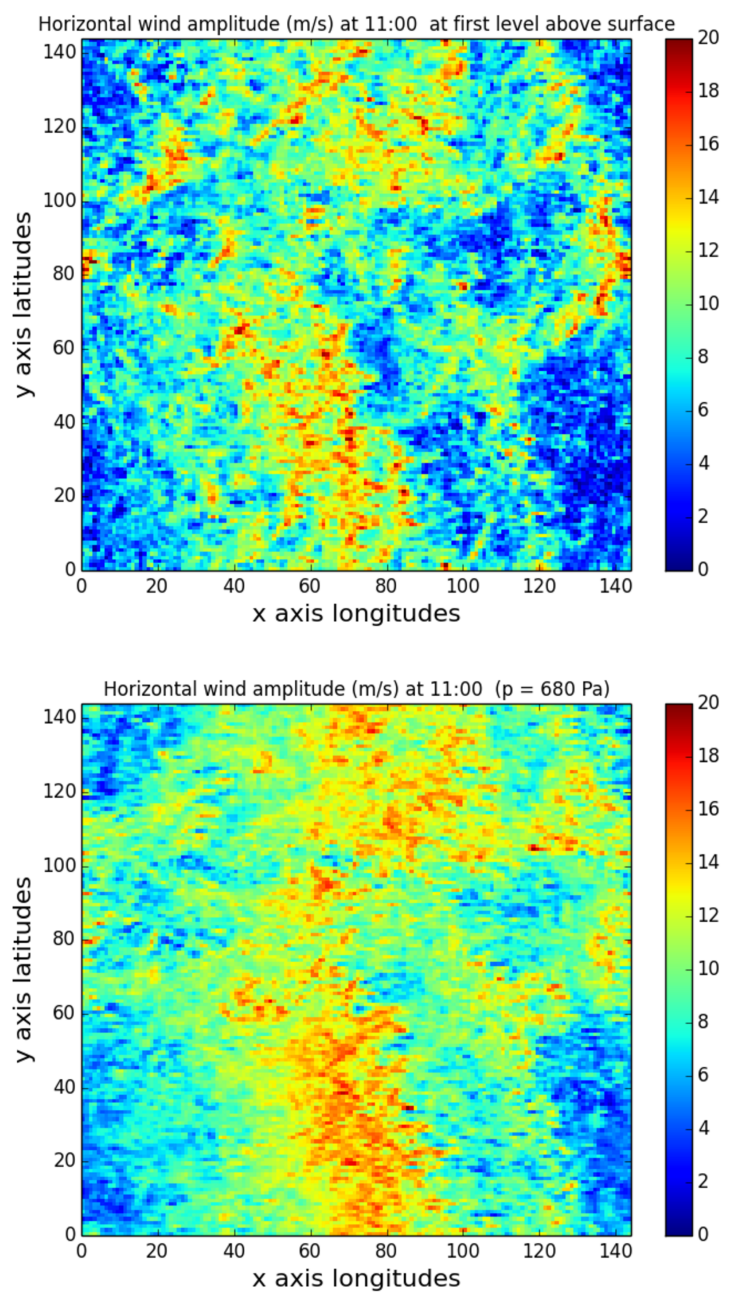

Figure 7. LMD (left) and SwRI (right) horizontal section of horizontal wind amplitudes at first level above surface (top) and at about $250 \mathrm{~m}$ above surface (bottom), at local time 11:00. Simulation with $15 \mathrm{~m} . \mathrm{s}^{-1}$ westward ambient wind. 
Geosci. Model Dev. Discuss., doi:10.5194/gmd-2016-241, 2016

Manuscript under review for journal Geosci. Model Dev.

Published: 16 November 2016

(c) Author(s) 2016. CC-BY 3.0 License.

(c) (1)

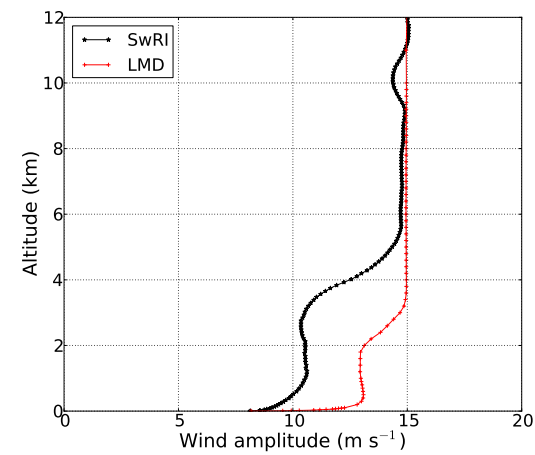

Figure 8. Horizontal wind profile in the SwRI (black) and LMD (red) LES models, between local times 11:00-12:00. 
Geosci. Model Dev. Discuss., doi:10.5194/gmd-2016-241, 2016 Manuscript under review for journal Geosci. Model Dev.

Published: 16 November 2016

(c) Author(s) 2016. CC-BY 3.0 License.

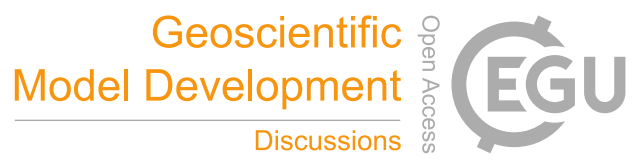

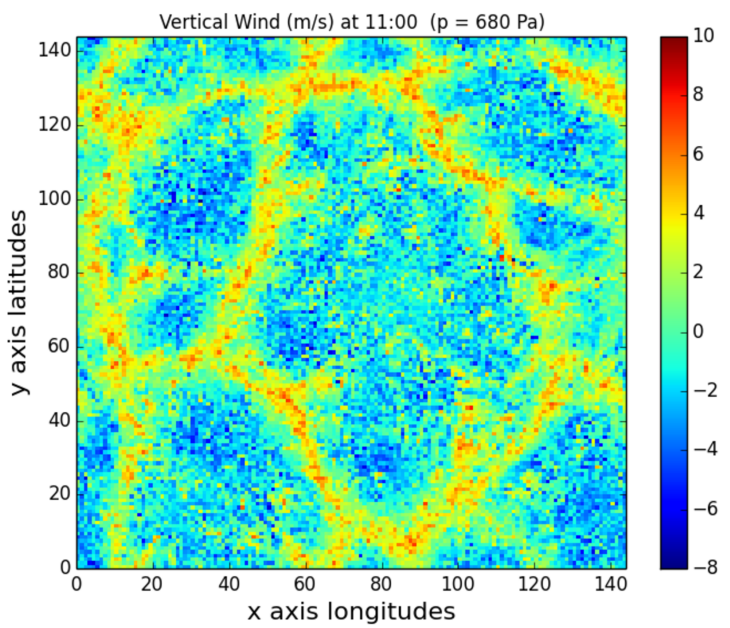
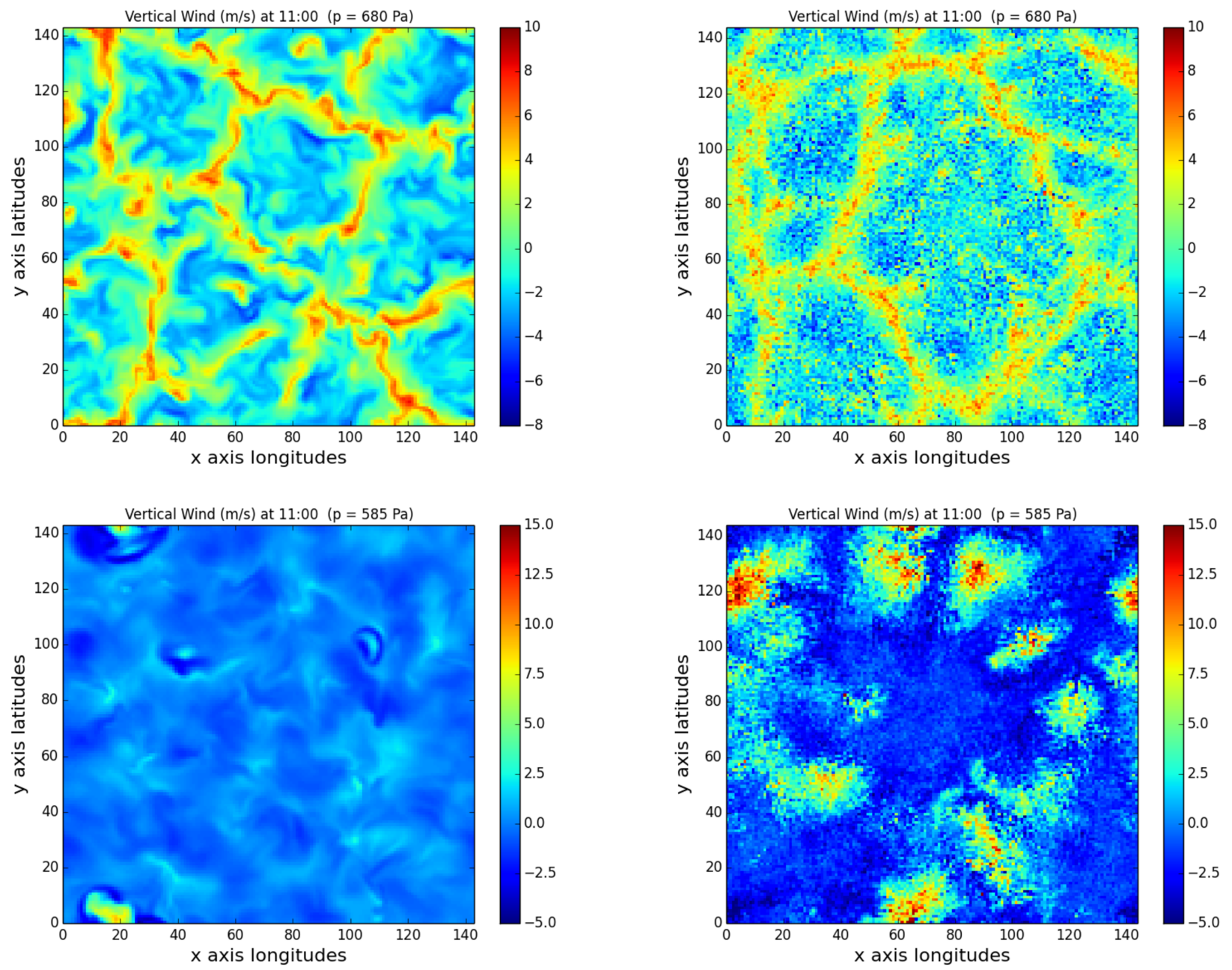

Figure 9. LMD (left) and SwRI (right) horizontal section of vertical velocity at about $250 \mathrm{~m}$ (top) and at about $2 \mathrm{~km}$ (bottom) above the surface, at local time 11:00. Simulations without ambient wind. 
Geosci. Model Dev. Discuss., doi:10.5194/gmd-2016-241, 2016

Manuscript under review for journal Geosci. Model Dev.

Published: 16 November 2016

(c) Author(s) 2016. CC-BY 3.0 License.

(c) (i)

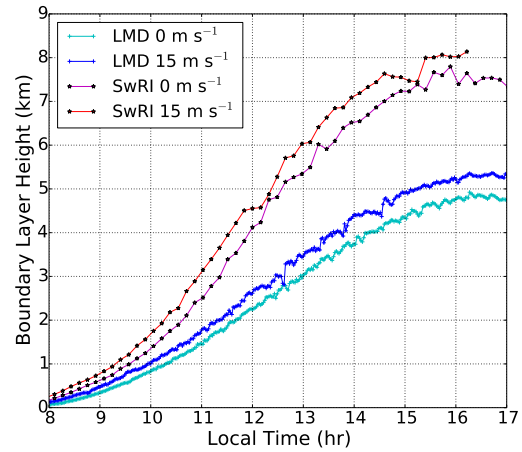

Figure 10. LMD and SwRI variations of boundary layer depth between local times 09:00 and 17:00 and altitudes above ground 0 and $9 \mathrm{~km}$. Simulations without ambient wind and with $15 \mathrm{~m} \cdot \mathrm{s}^{-1}$ ambient wind. 
Geosci. Model Dev. Discuss., doi:10.5194/gmd-2016-241, 2016 Manuscript under review for journal Geosci. Model Dev.

Published: 16 November 2016

(c) Author(s) 2016. CC-BY 3.0 License.

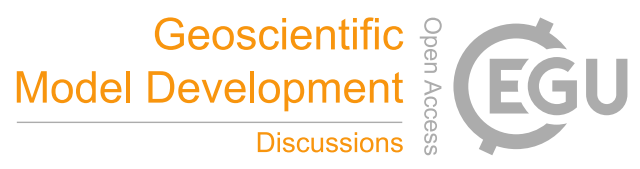

(c) (i)
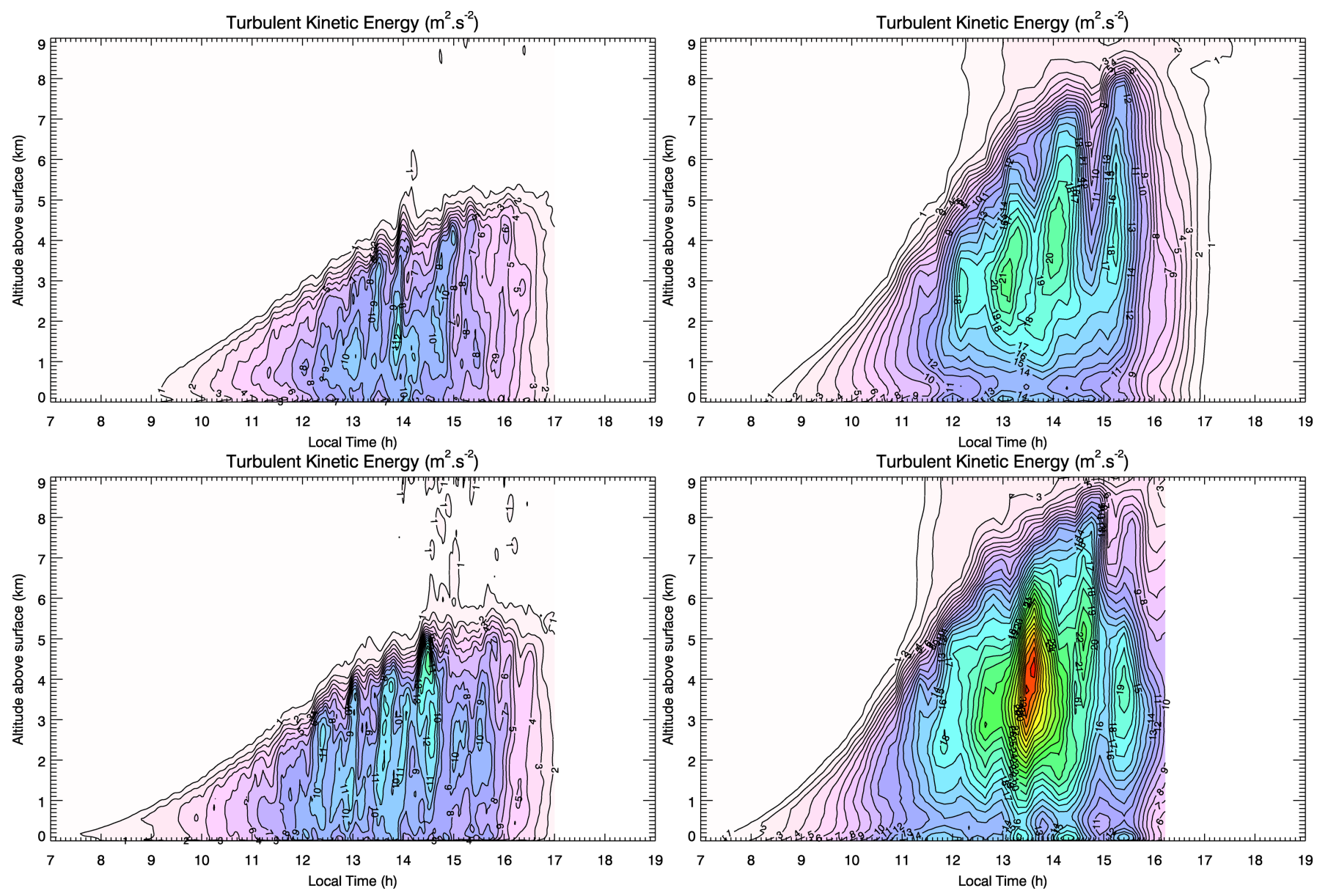

Figure 11. LMD (left) and SwRI (right) variations of turbulent kinetic energy between local times 07:00 and 19:00 and altitudes above ground 0 and $9 \mathrm{~km}$. Simulations without ambient wind (top) and with $15 \mathrm{~m} . \mathrm{s}^{-1}$ ambient wind (bottom). 
Geosci. Model Dev. Discuss., doi:10.5194/gmd-2016-241, 2016

Manuscript under review for journal Geosci. Model Dev.

Published: 16 November 2016

(c) Author(s) 2016. CC-BY 3.0 License.

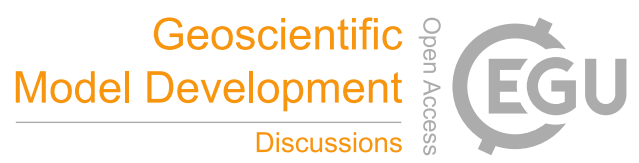

(c) (i)
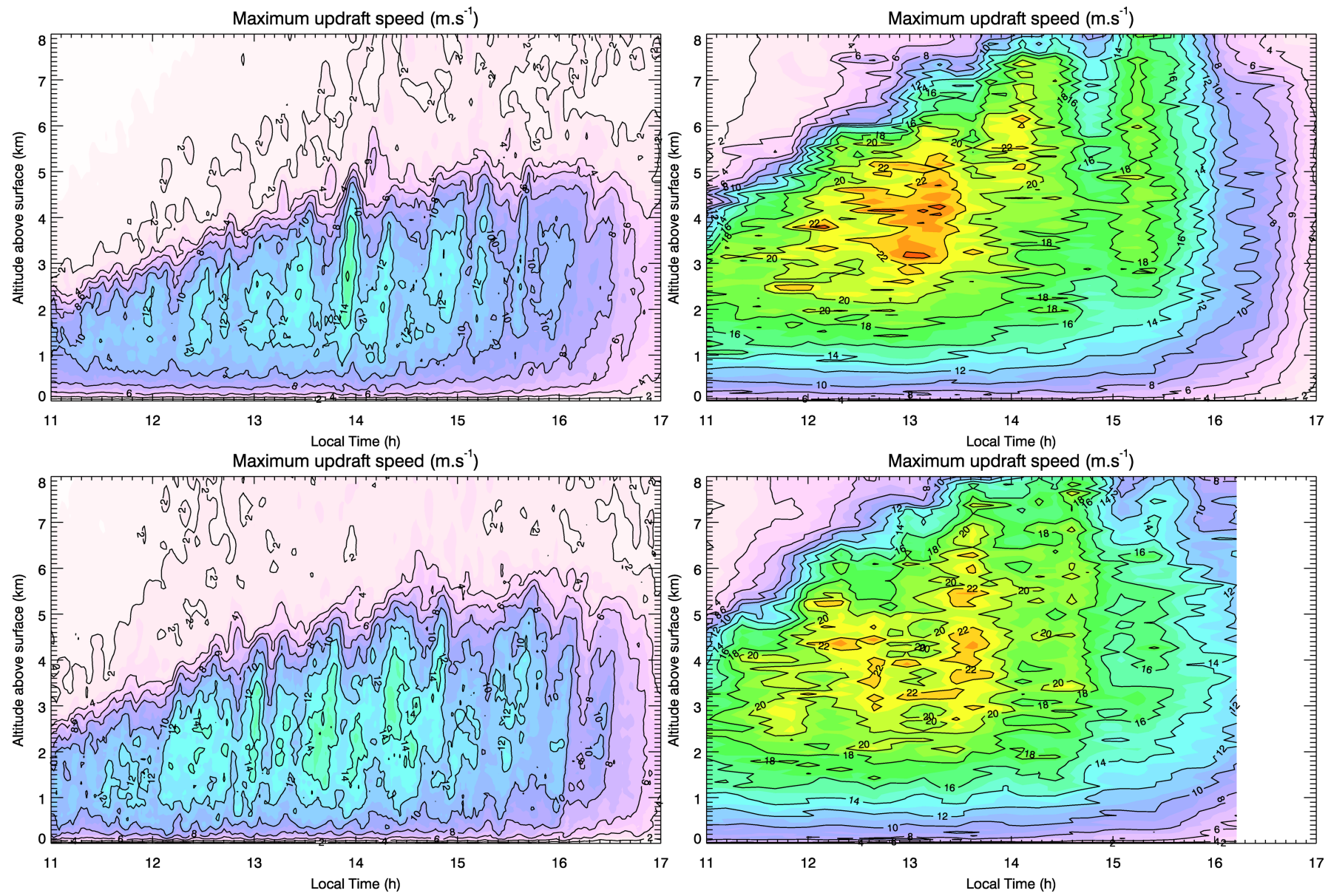

Figure 12. LMD (left) and SwRI (right) maximum speeds for convective updrafts reached in the simulation domain between local times 11:00 and 17:00 and altitudes above ground 0 and $8 \mathrm{~km}$. Simulations without ambient wind (top) and with $15 \mathrm{~m} . \mathrm{s}^{-1}$ ambient wind (bottom). 
Geosci. Model Dev. Discuss., doi:10.5194/gmd-2016-241, 2016

Manuscript under review for journal Geosci. Model Dev.

Published: 16 November 2016

(c) Author(s) 2016. CC-BY 3.0 License.

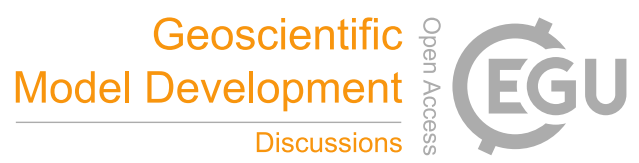

(c) (i)
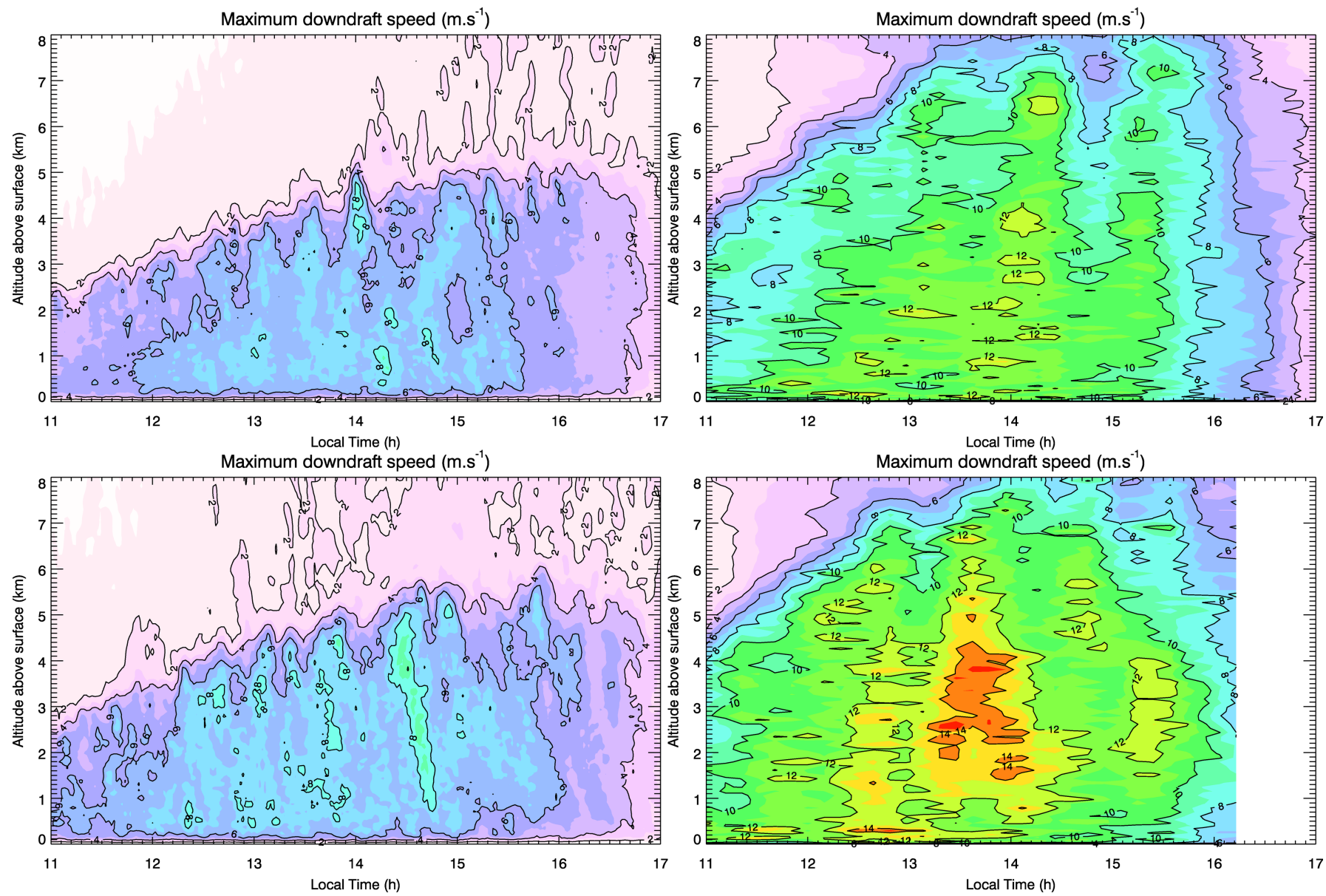

Figure 13. LMD (left) and SwRI (right) maximum speeds for convective downdrafts reached in the simulation domain between local times 11:00 and 17:00 and altitudes above ground 0 and $8 \mathrm{~km}$. Simulations without ambient wind (top) and with $15 \mathrm{~m} . \mathrm{s}^{-1}$ ambient wind (bottom). 
Geosci. Model Dev. Discuss., doi:10.5194/gmd-2016-241, 2016

Manuscript under review for journal Geosci. Model Dev.

Published: 16 November 2016

(c) Author(s) 2016. CC-BY 3.0 License.

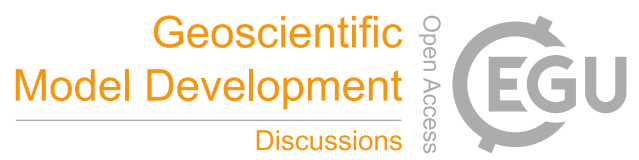

(c)

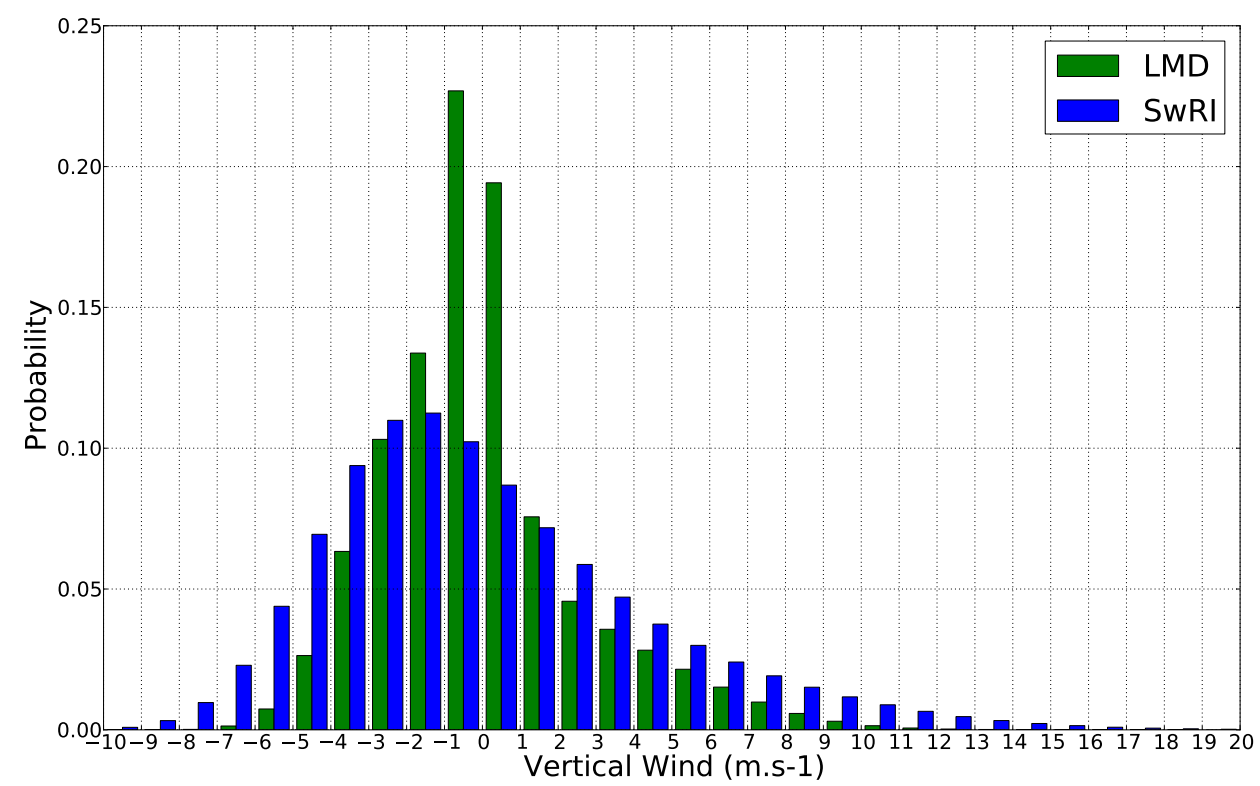

Figure 14. Histogram of vertical wind speeds for local times 13:00-14:00 and altitudes 250-5000 m. LMD results are in green, SwRI results are in blue. No ambient wind. 
Geosci. Model Dev. Discuss., doi:10.5194/gmd-2016-241, 2016

Manuscript under review for journal Geosci. Model Dev.

Published: 16 November 2016

(c) Author(s) 2016. CC-BY 3.0 License.

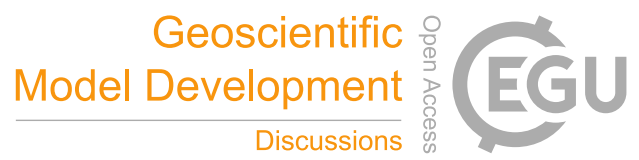

(c) $\underset{\mathrm{BY}}{\mathrm{B}}$

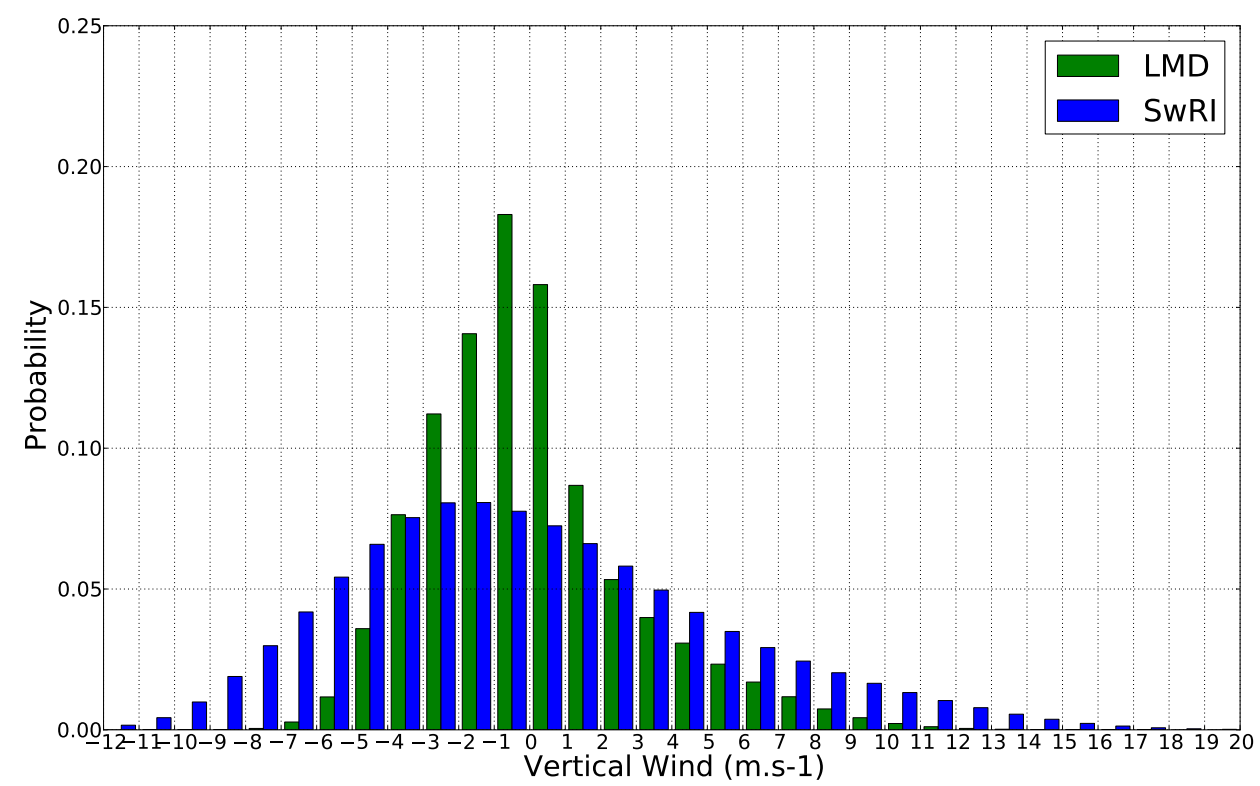

Figure 15. Histogram of vertical wind speeds for local times 13:00-14:00 and altitudes 250-5000 m. LMD results are in green, SwRI results are in blue. With $15 \mathrm{~m} \cdot \mathrm{s}^{-1}$ ambient wind. 
Geosci. Model Dev. Discuss., doi:10.5194/gmd-2016-241, 2016

Manuscript under review for journal Geosci. Model Dev.

Published: 16 November 2016

(c) Author(s) 2016. CC-BY 3.0 License.

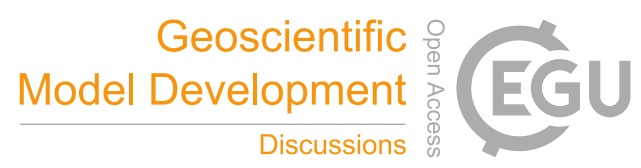

(c) (1)

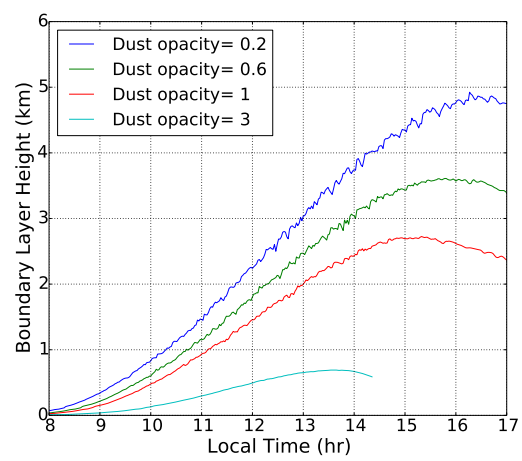

Figure 16. Evolution of the boundary layer depth for different dust optical depths (LMD LES)

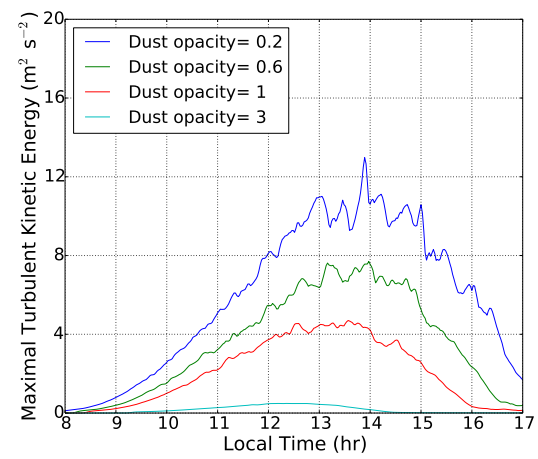

Figure 17. Evolution of the maximum turbulent kinetic energy for different dust optical depths (LMD LES)

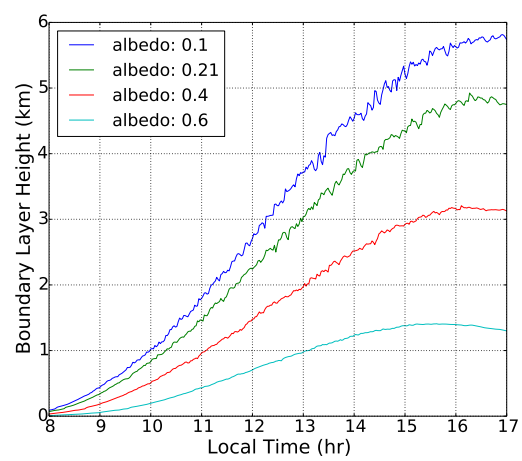

Figure 18. Evolution of the boundary layer depth for different surface albedo values (LMD LES) 
Geosci. Model Dev. Discuss., doi:10.5194/gmd-2016-241, 2016

Manuscript under review for journal Geosci. Model Dev.

Published: 16 November 2016

(c) Author(s) 2016. CC-BY 3.0 License.

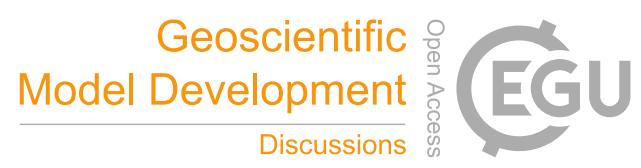

(c) (1)

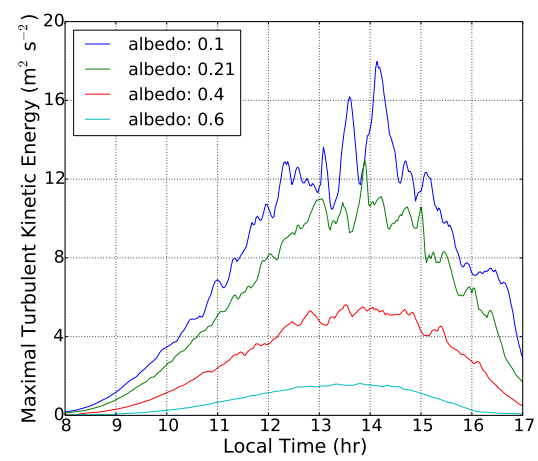

Figure 19. Evolution of the maximum turbulent kinetic energy for different surface albedo values (LMD LES)

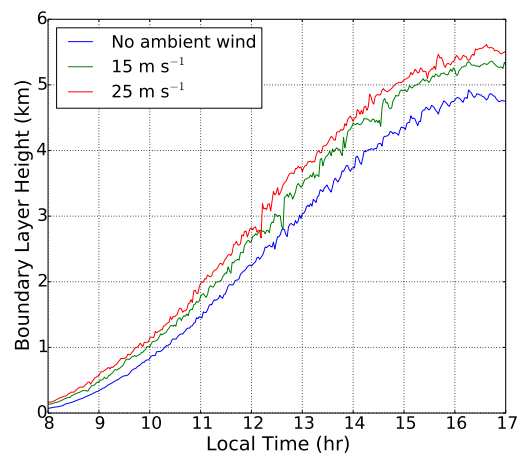

Figure 20. Evolution of the boundary layer depth for different large scale ambient winds (LMD LES)

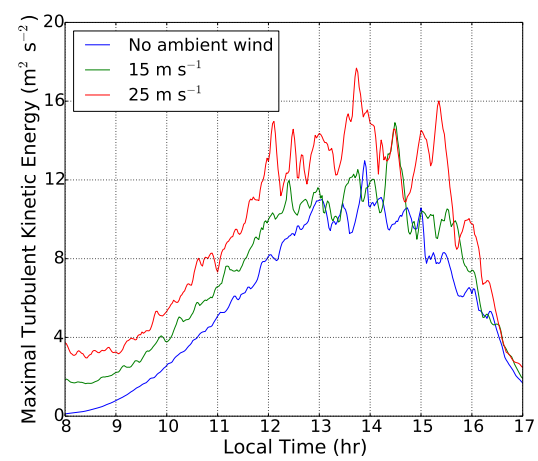

Figure 21. Evolution of the maximum turbulent kinetic energy for different large scale ambient winds (LMD LES) 